\title{
'Oro verde': la invención del paisaje forestal en Wallmapu/Araucanía, sur de Chile
}

\author{
'Green gold': the invention of the forest landscape \\ in Wallmapu/Araucanía, southern Chile
}

\section{Miguel Escalona Ulloa}

mescalon@uct.cl

Departamento de Ciencias Ambientales

Universidad Católica de Temuco (Chile)

\author{
Jonathan R. Barton \\ jbarton@uc.cl \\ Instituto de Geografía, IDS y CEDEUS \\ Pontificia Universidad Católica de Chile (Chile)
}

\section{Resumen}

Desde su incorporación a la República de Chile, Wallmapu/Araucanía ha sido objeto de importantes transformaciones territoriales. Una vez usurpada la tierra al pueblo mapuche, llegó el momento de explotar los fértiles valles e inexpugnables bosques para dar inicio al cultivo de trigo y su explotación que duró hasta inicios del siglo XX. Este trabajo busca indagar en la 'invención' del paisaje forestal del 'Oro Verde' en este territorio, utilizando para ello el enfoque de la ecología política histórica y el marco de 'paisajes de poder' en particular. A partir del análisis e interpretación de fuentes históricas, incluyendo cartografía, fotografía y textos, se (re)construye la trayectoria de este paisaje, haciendo énfasis en el rol de la ciencia, la promulgación de leyes, la creación de instituciones y la influencia de instituciones 
internacionales, quienes durante gran parte del siglo XX allanaron el camino para la llegada de grandes empresas, quienes bajo la dictadura iniciaron un 'boom' forestal sin precedentes. Las conclusiones apuntan a la importancia de transitar desde el concepto neutro de vocación territorial hacia la invención del paisaje como una construcción social basada en relaciones de poder que llevan a la dominación y la exclusión.

Palabras clave: ecología política histórica; paisaje; geografía histórica; geografía política.

\begin{abstract}
Since the incorporation of the Wallmapu/Araucanía territory into the Republic of Chile, important transformations in this territory have been taken place. Once the land was usurped from the Mapuche people, fertile valleys and dense forests were replaced by wheat cultivation until the early twentieth century. This article explores the 'invention' of so-called 'Green Gold' forest landscape in this region, using historical political ecology and a 'landscapes of power' framework. Based on the analysis and interpretation of historical sources, including cartography, photography and texts, we reconstruct the historical trajectory of this landscape, emphasizing the role of science, the enactment of laws, the creation of new institutions and the influence of international organizations. These influences paved the way for large forestry firms to emerge, primarily under dictatorship (1973-1989), which in turn generated an unprecedented plantation forestry 'boom' that transformed the regional landscape. The conclusions highlight the importance of shifting from a neutral concept of territorial attributes to the invention of landscapes, as a social construction based on power relations that lead to domination and exclusion.
\end{abstract}

Key words: historical political ecology; landscape; historical geography; political geography.

\title{
1 Introducción: la invención del paisaje forestal
}

A lo largo de la historia las ideas de 'progreso' y 'desarrollo' han movilizado profundas transformaciones territoriales. Estas ideas nacieron en la confianza de la llustración de que, a través de la aplicación sistemática de la razón a la sociedad, podrían crearse condiciones racionales de la vida humana (Iggers, 1965; Agnew, 2003; Escobar, 2007). Esta motivación resultó central para los Estados-Nación que se construyeron durante gran parte del siglo XIX en América Latina (Galeano, 2004; Hevilla, 2007). Chile no estuvo ajeno a esta situación. El interés del Estado y de los grupos dominantes fue adentrarse en el sur del país y descubrir aquellas 
bondades presentes en espacios dotados de una naturaleza exuberante, que pudieran formar parte de algún ciclo productivo e iniciar su explotación. Esta tarea fue realizada por diversos naturalistas entre los cuales destacan Ignacio Domeyko, Gustave Vernory y Edmond Smith, quienes durante el siglo XIX emprendieron travesías para adentrarse al Wallmapu/Araucanía. ${ }^{1}$

Las descripciones que estos cronistas construyeron pueden ser analizadas como un relato conmovedor, de esfuerzo y templanza que permitió ampliar el conocimiento del mundo a través de la descripción del territorio y del pueblo mapuche, habitante ancestral de estas tierras. Una lectura más crítica permite reconocer que estas acciones son propias del colonialismo que se llevó a cabo en la antigua 'frontera', ya que la información recabada en estos documentos contribuyó a la usurpación de la tierra al pueblo mapuche e invisibilización de su cultura. Estas acciones, junto a litigios permanentes por las tierras durante los siglos XIX y XX, además de los intentos por lograr la aculturación y promover la negación del pueblo mapuche, dieron origen al conflicto histórico que se mantiene hasta nuestros días (Mariman et al., 2006; Crow, 2013; de la Maza, 2014; Nahuelpan et al., 2012; Di Giminiani, 2012, 2015).

La fértil tierra araucana se ha constituido sistemáticamente en un medio de producción que ha sido necesario adquirir, controlar y transformar. A finales del siglo XIX fue utilizada para producir granos, durante el siglo XX y luego de la explotación indiscriminada del bosque nativo, supo acoger diversas especies forestales para dar cabida a una economía basada en las plantaciones (Escalona \& Barton, 2020). Los estudios respecto al paisaje forestal asociado a la extensión e intensificación del crecimiento de las plantaciones forestales de pino y eucaliptus en el sur de Chile se han concentrado principalmente en el rol que ha tenido la región del Biobío (Mamalakis, 1982; Clapp, 1998; Camus, 2006; Klubock, 2014; Carrasco \& Aliste, 2017), dejando de lado otros espacios regionales (Figura 1). Este trabajo viene a completar este vacío ya que busca analizar la trayectoria asociada al incremento de estas plantaciones a través de la construcción del paisaje forestal del 'Oro verde' en Wallmapu/Araucanía y explorar las relaciones de poder detrás de esta construcción social.

La 'invención' de este paisaje surge con mayor fuerza en momentos específicos de la historia regional. En un primer momento las grandes selvas presentes en este territorio fueron objeto de adulación por su inmensidad y belleza. No obstante, con el paso del tiempo se transformaron en

1 El territorio examinado en este artículo lleva el nombre oficial, según el Gobierno de Chile, de Región de La Araucanía. Sin embargo, esta designación es producto de la conquista de este territorio, conocido como Wallmapu. La co-existencia de los dos nombres revela la tensión que existe actualmente entre las demandas de los Mapuche y la designación oficialista del Estado chileno. Es por esta razón que son combinados en este texto. 
un 'estorbo' para la implementación de nuevos ciclos productivos, situación que hizo necesario despejarlos mediante la quema y el roce. Estas acciones ocurrieron en forma simultánea a los discursos científicos que hicieron énfasis en las condiciones climáticas que presentaban estas tierras para acoger otras especies. En este contexto, se promulgaron leyes, se crearon instituciones (ej. CORFO) y, mediante la influencia de organismos internacionales (ej. CEPAL), fue posible proyectar el crecimiento del país a partir de las plantaciones forestales de pino y eucaliptus, configurando entonces el paisaje del 'Oro verde'.

\section{Figura 1. Área de estudio, Región de La Araucanía}

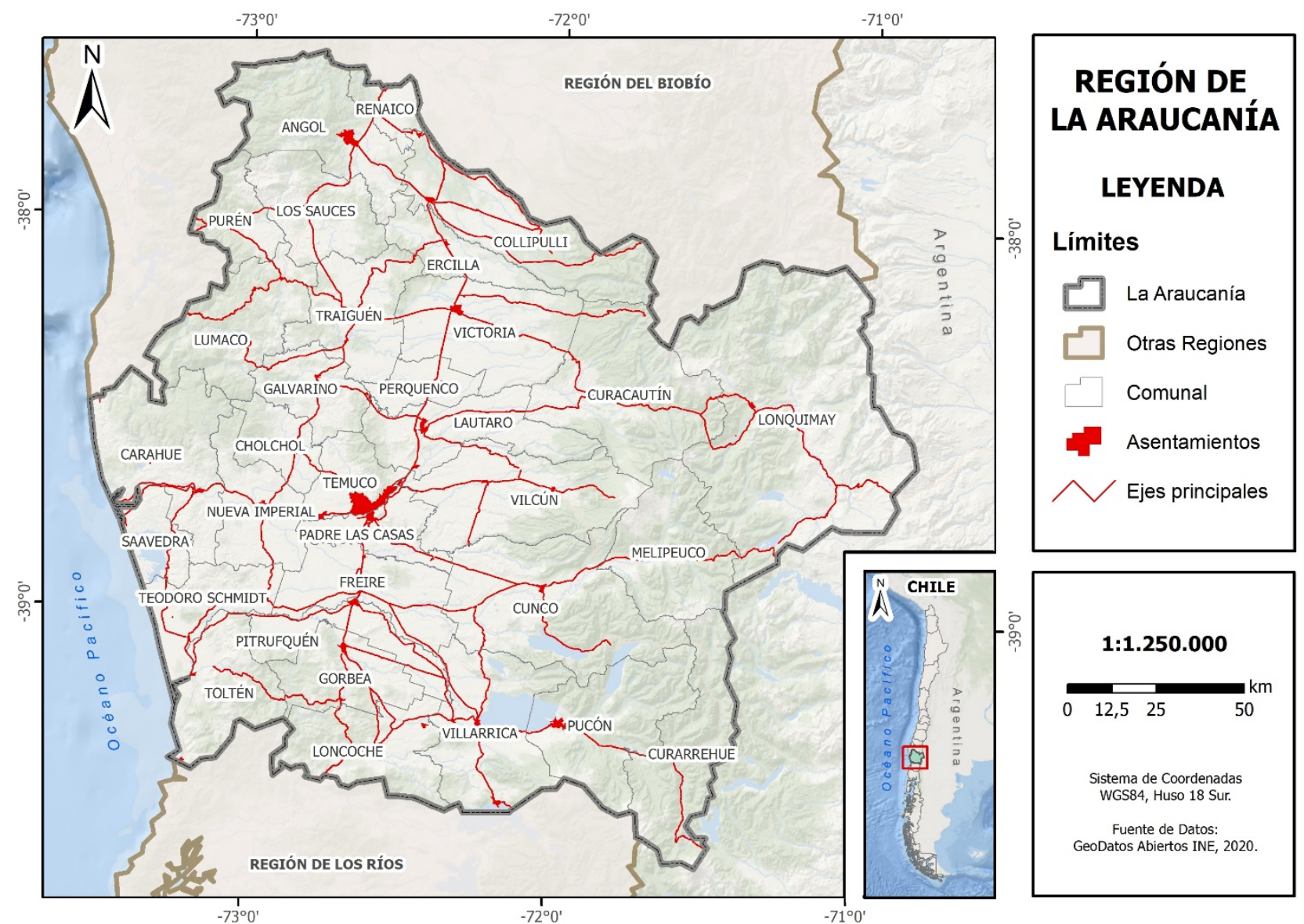

Fuente: elaboración propia

La estructura del artículo incluye inicialmente un contexto teórico y metodológico que sustenta la trayectoria de la 'invención' del paisaje forestal del 'Oro verde' en Wallmapu/Araucanía, para luego detenerse en cuatro momentos específicos de la historia regional. El primero abarca desde 1870 a 1900, cuando surgen las primeras referencias a la existencia de especies arbóreas de rápido crecimiento ubicadas en otros hemisferios, junto con algunos relatos que describían el bosque araucano. El segundo, que se extiende desde 1900 a 1930, hace énfasis en el proceso de la quema y roce que afectaron al bosque nativo y la influencia del 
conocimiento científico en el arribo de las plantaciones forestales de pino y eucaliptus. El tercer momento indaga en aquellos instrumentos que permitieron la expansión de las plantaciones desde 1930 a 1960, y las acciones que surgen al amparo de los discursos asociados a la industrialización del país. El cuarto momento analiza el 'boom' forestal en la región durante el periodo 1960 a 1990, y pone el acento en la promulgación del Decreto 701 y la expansión territorial de las plantaciones. Finalmente, se entregan antecedentes actuales de los efectos de las plantaciones en las comunidades mapuche. Los periodos antes señalados se contextualizan dentro de un argumento basado en el marco de los 'paisajes de poder', que permite comprender la hegemonía que está implícita en la 'invención' del paisaje forestal del 'Oro verde'. Las conclusiones apuntan a la importancia del contexto histórico para comprender como las relaciones de poder han incidido en la construcción de este tipo particular de paisaje, ampliando con ello las fronteras de extracción dando continuidad al proceso de acumulación, situación que ha posicionado a la actividad forestal como otra arista del actual conflicto EstadoPueblo mapuche.

\section{Contexto teórico y perspectivas metodológicas asociadas a la ecología política histórica y los paisajes de poder}

Para indagar en la 'invención' del paisaje forestal del 'Oro verde' se utiliza como campo de investigación la dimensión histórica de la ecología política. La ecología política, desde sus inicios, ha planteado que los cambios y transformaciones ambientales surgen por decisiones políticas (Blaikie \& Brookfield, 1987). Busca entender las asimetrías que surgen de la interacción humano-ecológica, donde priman concepciones que promueven la apropiación de la naturaleza y la instalación de modelos de desarrollo basados en la extracción (Neumann, 2011; Batterbury, 2015). La perspectiva crítica de la ecología política ha influido también en un amplio movimiento social y político que tiene como propósito lograr la justicia socioecológica (Perrault et al., 2015; Martínez Alier, 2015), que se ha sustentado en la politización del nexo entre el ser humano y la naturaleza (Swyngedouw, 2011; Bustos, Prieto \& Barton, 2014). Si bien la ecología política ha contribuido reflexionar sobre los conflictos socioambientales contemporáneos, no ha insistido suficientemente en la perspectiva histórica de estos conflictos y las transformaciones ocurridas a nivel territorial.

La ecología política histórica aborda este vacío ya que, según Karl Offen (2004, p. 21), “busca interpretar la relación sociedad-naturaleza en retrospectiva, considerando su dimensión material, ideológica, legal y espiritual. Tiene como propósito, comprender los cambios espaciales y 
temporales producto de esta relación". De esta manera, se releva la importancia de incorporar procesos históricos en la comprensión de las ecologías políticas contemporáneas, ya que proporcionan un contexto adecuado para analizar las diferentes configuraciones socioecológicas y asimetrías de poder (Davis, 2009, 2015, 2016). Esta dimensión de la ecología política busca explicaciones históricamente localizadas a los conflictos contemporáneos, para evitar lecturas apolíticas, a-históricas y a-territoriales (Mathevet et al., 2015; McKinnon \& Colleen, 2016). Diana Davis (2009, p. 286) señala la importancia de entender que las construcciones sociales actuales tienen raíces antiguas: "Lo que estos estudios revelan es la importancia que alcanzan las ideas sobre el mundo natural y, la naturaleza de los cambios ambientales desarrollados bajo el imperialismo occidental, el colonialismo y otras formas más sutiles de control". Para analizar la trayectoria de este paisaje se utilizará la perspectiva de 'paisajes de poder', que permite comprender que el paisaje no surge de manera neutra ni casual, sino a partir de una hegemonía imperante (Mitchell, 2001; Olwig \& Mitchell, 2009; Escalona, 2019; Escalona \& Barton, 2020).

El paso inicial al momento de abordar el estudio del paisaje es reconocer que el ser humano se encuentra contenido en el paisaje. Este concepto tensiona permanentemente los postulados básicos del conocimiento, ya que se posiciona tanto en el debate referido a las ciencias de la naturaleza como a las ciencias de la cultura, así como también, en las perspectivas empíricas y racionales que nos permiten comprender nuestro entorno (Escalona, 2019). Nuestra relación con el paisaje está compuesta no solo por lo que se sitúa delante de nuestros ojos, sino por lo que está en nuestras mentes, es decir, el paisaje, en cuanto hecho cultural, forma parte de las personas, se constituye en el fondo de nuestra existencia colectiva, es un marco que nos sitúa y también nos rodea, apoya y facilita los complejos procesos cotidianos (Maderuelo, 2005; Jackson, 1989; Meinig 1979). En otras palabras, los distintos grupos humanos que habitan un espacio influyen en el paisaje porque es una realidad física y también una representación que culturalmente nos hacemos de él (Nogue, 2010; Shamma 1997; Olwig, 1996).

Los enfoques tradicionalmente utilizados en el estudio del paisaje surgen de concepciones antagónicas, vale decir, el paisaje entendido como naturaleza/cultura, material/inmaterial (Husserl, 1962; Muir, 1998; Cassirer, 2014). Con el paso del tiempo se fue transitando desde aquellas ideas cartesianas del paisaje hacia ámbitos subjetivos que se enmarcaron en perspectivas más bien fenomenológicas (Sauer, 1925; Lowenthal, 1961; Meinig 1979; Cosgrove \& Daniels, 1988). Estas generaron la base para comprender el paisaje desde la vivencia, donde el ser humano forma parte de él y se constituye en un agente transformador (Tuan, 1974; Ingold, 1993; Bhabha, 2002; Cassirer, 2014; Simmel, 2012) (Figura 2). En este contexto, han surgido 
diversas iniciativas que busquen su protección, entre estas destacan el Convenio Europeo del Paisaje, cuyo propósito es implementar políticas para su conservación y gestión (Convenio europeo del paisaje, 2000). A ello se debe sumar la Iniciativa Latinoamericana del Paisaje (LALI), que establece una declaración de principios éticos para promover el reconocimiento, la valoración, la protección, la gestión y la planificación sostenible del paisaje latinoamericano.

Figura 2. El marco teórico-conceptual de los 'Paisajes de Poder'

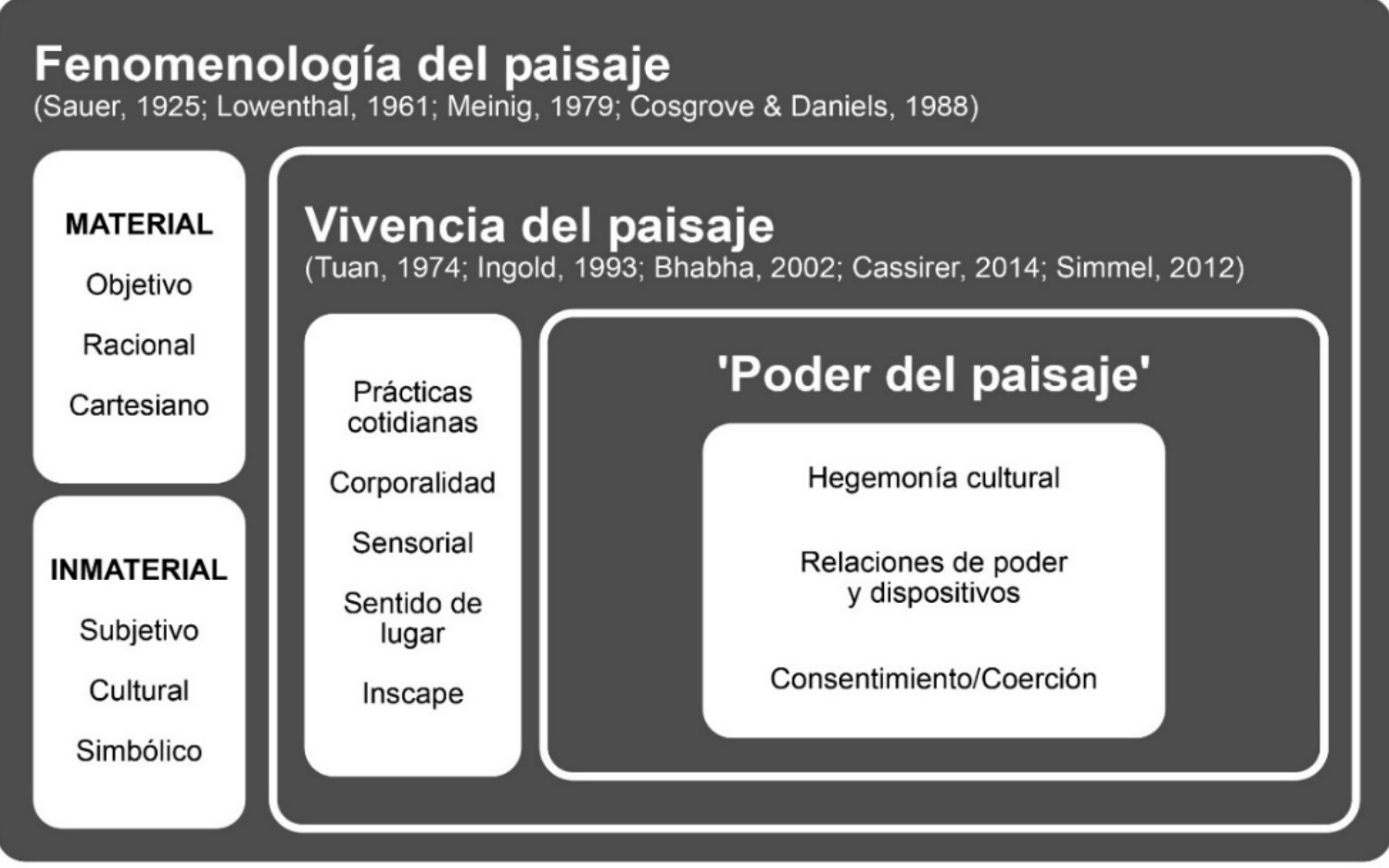

Fuente: Escalona \& Barton (2020)

Este trabajo plantea un marco de análisis asociado a los paisajes de poder, que se nutre de las anteriores posiciones, pero propone un enfoque más crítico al reconocer que el vínculo que surge entre el paisaje y el poder se encuentra influenciado por aspectos económicos y políticos (Mitchell, 2002, 2008). En ellos el rol de la hegemonía cultural (Femia, 1987; Gramsci, 1999; Martin, 2002) resulta clave, ya que refleja las formas en que se ejerce la coerción y el consentimiento para consolidar una forma particular de construcción y ocupación del paisaje que se expresa a través de las transformaciones territoriales. Estas formas de control incluyen dispositivos provenientes de la ciencia, la cartografía, el derecho, la literatura, el arte y la fotografía. Este trabajo busca posicionar al paisaje como un constructo histórico, interesado e imprescindible, que permite trazar aquellos dispositivos utilizados en la 'invención' del paisaje forestal del 'Oro verde', desde un sentido común dominante. 
El uso de una metodología mixta resultó crucial para llevar a cabo este trabajo que consideró el análisis e interpretación de fuentes históricas de tipo documental, mapas y fotografías. El análisis del discurso fue utilizado para conocer cómo este se estructura y se posiciona en los distintos actores sociales. Para examinarlos se enfatizó en aquellos lenguajes figurativos que hacen que los argumentos sean más o menos efectivos (Rydin, 2003). La búsqueda en cada uno de los documentos estuvo orientada a identificar palabras claves y relatos que exponen aquellas ideas que sustentaron la invención del paisaje forestal en Wallmapu/Araucanía. Para lograr aquello se utilizaron métodos interpretativos que consideran la interacción entre tres elementos: crítica, triangulación y hermenéutica (Donnelly \& Norton, 2011). La crítica, permitió identificar las maneras en que una fuente pudo estar incompleta y sesgada, para ello se determinó su grado de confianza a través de la identificación de la autoría del texto. La triangulación, buscó combinar las percepciones de diferentes fuentes y por medio de la comparación, construir las interpretaciones. La hermenéutica, permitió considerar el contexto cultural, social y temporal en el que las fuentes fueron producidas (Kipping et al., 2014).

El análisis e interpretación de mapas permitió identificar los cambios a nivel territorial ocasionados por los dispositivos utilizados para instalar el 'Oro verde'. Este trabajo consideró que los mapas son representaciones selectivas de la realidad (Schlögel, 2007), de ahí que existan elementos ausentes en ellos que deben ser develados. Para alcanzar tal propósito se buscó 'deconstruir el mapa', teniendo en consideración las "reglas cartográficas, deconstrucción y texto cartográfico y el poder interno y externo de ellos" (Harley, 1989). En cuanto a las reglas cartográficas, se consideraron aquellos procedimientos técnicos que operan en la representación cartográfica, así fue posible identificar aquellos elementos que se disponen en el centro del mapa o en su periferia, se hizo énfasis también en el tamaño de los signos, los límites y colores. Para la deconstrucción y texto cartográfico, fue necesario observar los elementos desde la retórica cartográfica asociada a la creación de jerarquías y simbolización, la selección de los elementos que se presentan y no se presentan, el detalle de la topografía y la escala utilizada. El poder externo e interno del mapa, implicó relacionarlos con quien lo encargaba (Estado, instituciones privadas), los cuales buscaban en su elaboración controlar el conocimiento y resguardar cierta información. El interno, tuvo que ver más con el proceso cartográfico, es decir, las normas, jerarquías y estilos que fueron establecidas sobre el territorio (Del Casino \& Hanna, 2006; Vermeylen et al., 2012).

El estudio de las fotografías fue realizado desde la semiótica y consideró: la heurística, el análisis técnico e iconográfico y la interpretación iconológica (Burke, 2001). En cuanto a la heurística, esta 
se orientó a un trabajo de búsqueda de archivos que permitió la localización y selección de las fuentes fotográficas. El análisis técnico, implicó una investigación de la procedencia y trayectoria del documento fotográfico. Para ello fue necesario registrar su existencia, su origen, la época y el lugar del que procede. El análisis iconográfico, permitió investigar acerca de los elementos icónicos de cada imagen con el fin de distinguir su contenido, figuras, personificaciones o atributos, símbolos y alegorías. La interpretación iconológica, este proceso se realizó de manera simultánea al análisis técnico, con el objeto de profundizar en el significado de la fotografía. Esto sólo fue posible realizarlo a partir de observarlas de manera reflexiva y desde una perspectiva crítica, para lograr identificar la información que va más allá de lo que la autora o el autor está exponiendo en la imagen (Barthes, 1986).

Las fuentes documentales, mapas y fotografías utilizadas fueron extraídas de la Biblioteca Nacional y el Archivo Nacional ubicados en la ciudad de Santiago de Chile, además, del Archivo Regional de La Araucanía (ARA) ubicado en la ciudad de Temuco y también algunas bibliotecas y centros culturales de la Región de La Araucanía.

\section{Trayectoria del paisaje forestal del Oro Verde (1870-1990)}

El paisaje forestal surge en la región a partir de una serie de decisiones políticas que tuvieron como propósito aprovechar las condiciones naturales de este espacio regional para instalar nuevos ciclos productivos. Los bosques y selvas de antaño fueron reemplazados por especies exóticas que se adaptaron rápidamente a estas tierras, favoreciendo la construcción de un paisaje donde predominará la actividad forestal.

En este contexto, es preciso señalar que previo a la anexión de este territorio por parte del Estado chileno (1860-1881) y el arribo de la actividad forestal, existió un paisaje asociado al habitar del pueblo mapuche en este lugar. Sus principales características han sido descritas por cronistas que durante los siglos XVI y XVII observaron como este pueblo utilizaba el espacio a total libertad, sin apreturas, donde cada cacique vivía con sus vasallos en grandes extensiones de terreno y siempre vinculados a valles, montañas y ríos. De hecho 'nombraban' su espacio como Lauquenmapu, esto es, país marítimo, Lelgunmapu, país llano, Inapiremapu, país subandino, y Piremapu, país andino (De Ovalle, 1646; Molina, 1788). La vivencia del pueblo mapuche que se transmite a partir del paisaje que habitan, permite reconocer el vínculo entre la materialidad de los hitos naturales con aquellos elementos simbólicos propios de este pueblo. 
Durante finales del siglo XIX, el Estado chileno, apoyado por las élites agrícolas, políticas e intelectuales movilizaron acciones que permitieron la explotación de los recursos naturales presentes en este territorio. Estos acontecimientos posibilitaron la construcción de un nuevo paisaje: el Granero de Chile, que se instaló en la antigua frontera araucana.

\subsection{Preparando el camino para el arribo del 'nuevo' bosque (1870-1900)}

Ya conocida la fértil naturaleza araucana que permitió asentar el paisaje del 'Granero de Chile' (Escalona, 2020), se llevaron a cabo acciones para la instalación de nuevos ciclos productivos. Los bosques y selvas pasaron a estar en la mira de la élite capitalista, quienes mediante discursos hegemónicos justificaron la explotación del bosque nativo y en las décadas siguientes promovieron la introducción de nuevas especies promoviendo así la 'invención' del paisaje forestal del 'Oro verde'. Este cambio de rumbo también fue producto de una baja en la demanda de trigo debido al colapso de la 'fiebre del oro'.

El inicio de este proceso se remonta a las últimas décadas del siglo XIX, periodo en el que surgen experiencias innovadoras respecto al uso del eucaliptus como árbol propicio para los colonos. El Boletín de la Sociedad Nacional de Agricultura de 1875 transmite este interés:

Puede uno hacerse cargo fácilmente de los servicios que los bosques de Eucaliptus pueden prestar plantándoles alrededor de la morada de los colonos, de manera que estén siempre a su disposición (...) el eucaliptus será uno de los poderosos agentes de colonización para todo país nuevo (El Campesino, 1875, p. 314).

El atributo que más se destaca del eucalipto es su capacidad de adaptación. Tal como los ingleses lo hicieran en la colonización de África, su uso podría masificarse en otros espacios a colonizar ya que eran fáciles de plantar. La situación por la que pasaba la antigua 'frontera araucana' era perfecta para tal acción. El plan de 'pacificación' de Cornelio Saavedra estaba en plena ejecución y su propósito era someter al pueblo mapuche para lograr el control de este territorio. Las ideas planteadas en el Boletín resultaban propicias ya que podían ser ejecutadas en aquellos lugares 'inhóspitos' que existían en el país y sobre los cuales se llevaban a cabo acciones de colonización que incluían el control de la naturaleza.

Durante este mismo periodo surgieron relatos que aludían a la riqueza e inmensidad del bosque presente en estas tierras. Los bosques fueron observados desde un principio como un 'obstáculo' que era necesario superar para acceder a las tierras. Sin embargo, había observadores críticos del mismo proceso. Isidoro Errazuriz señalaba: 
La huella del hombre y de sus instintos de destrucción salvaje está estampada en los más tupido del bosque. A cada paso, vemos desfilar, entre masas de verduras llenas de vida y de vigor, grupos de árboles destruidos y ennegrecidos por el roce, que han quedado en pie como protestando contra la barbarie de los nuevos ocupantes de la Araucanía (Errázuriz, 1892, p. 15).

Este agente de colonización observaba con espanto cómo los 'nuevos' ocupantes que arriban a este lugar utilizaban la quema como una práctica usual. La explotación del bosque araucano también contribuyó a su reemplazo, son reiterados los relatos donde se describen modernos aserraderos. La crónica de Julio Mansoulet comentaba este proceso de mecanización:

Una de las más hermosas propiedades de la región boscosa de la subdelegación de Victoria, es de propiedad del señor Ezequiel Lavanderos (...) en este fundo existe un establecimiento de elaboración de maderas en gran escala. Motores de poderosa fuerza de la conocida casa americana Waterous Engine Works y C., Brantford, Canada, suministran la fuerza motriz necesaria para estas labores (Mansoulet, 1893, p. 48).

Este tipo de narrativas reflejan la época de oro por la cual pasaba la región en términos productivos. Fértiles tierras, densos bosques y tecnología de última generación se transformaban en pieza clave para explotar su naturaleza. La explotación del bosque que se llevaba a cabo por los colonos que habían llegado a la provincia de Malleco quedó plasmada en el Censo de 1895:

El gobierno ha destinado gran parte de esta provincia para los colonos nacionales (...) sus habitantes se dedican al cultivo de trigo y a la corta de maderas, industrias que dejan a los que la explotan excelentes utilidades (p. 3).

A pesar de estas acciones, el bosque permaneció inalterado en algunos sectores de la región. Gustave Verniory, ingeniero belga que lidió con él al momento de construir las primeras líneas de ferrocarril, señalaba:

Me pregunto si estoy soñando, si soy verdaderamente yo mismo quien se encuentra ante esta fabulosa vegetación. Jamás me imaginé estos árboles desconocidos, estas plantas trepadoras originarias del país, cubiertas de flores deslumbrantes (Verniory, 2001, p. 25) 
Verniory, encomendado por el Estado, penetró en estos bosques y obtuvo de él la materia prima para construir puentes y durmientes. Este ingeniero se enfrentó a un espacio donde predominaba un paisaje originario que debió ser transformado para llevar adelante la 'invención' del paisaje forestal del 'Oro verde'. La Figura 3 muestra la construcción de la línea férrea en Temuco. De fondo se aprecia el cerro Conun Huenu, talado completamente.

\section{Figura 3. Temuco (febrero de 1895)}

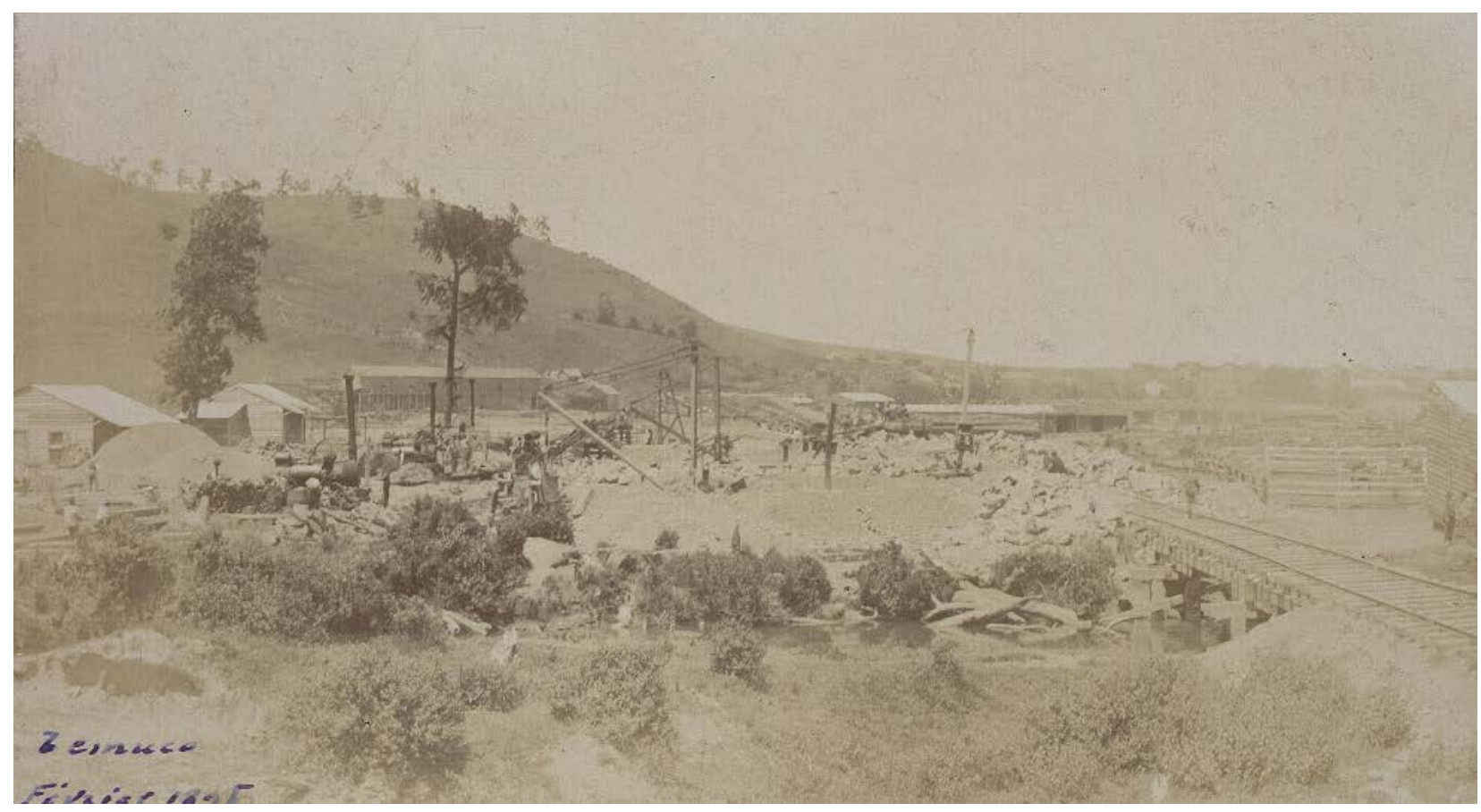

Fuente: Colección fotográfica Gustave Verniory. Musée du QuiaiBranly Jacques Chirac

El período de coerción y control previo a 1900 implicó la apertura de la región hacia colonos y migrantes, respaldados por el Estado chileno, en alianza con un brazo técnico de científicos e ingenieros. La construcción de una 'frontera' que había que desarrollar a través de nuevos sistemas productivos (Klubock, 2014), como en el caso del 'Granero de Chile', fue impuesto sobre un paisaje indígena, que requirió su silenciamiento y expulsión. El paisaje fue construido como un objeto natural y, a la vez, con un propósito o vocación territorial: sin sujetos, deshabitado y sin historia.

\subsection{Ciencia y legislación puesta a disposición de la 'plantación' (1900-1930)}

El nuevo siglo trajo una mayor intensidad en la expansión de zonas productivas, las alusiones al uso del fuego con el propósito de quemar el bosque continuaban siendo mencionadas por algunas publicaciones. El Campesino, Boletín de la Sociedad Nacional de Agricultura (1901), indicaba: 
Al principio hubo necesidad de quemar los bosques para defenderse y protegerse contra los malones de los indios, más tarde fueron, los agricultores quienes han encontrado que las quemazones son el mejor medio de desprenderse más pronto de ellos (p. 984).

El panorama del bosque nativo en Chile era complejo. Con el propósito de indagar en nuevas técnicas de manejo fue contratado durante el gobierno de José Manuel Balmaceda uno de los científicos más importantes en el ámbito forestal, Federico Albert (Camus, 2006). En sus primeras andanzas por el país mencionaba:

Causa espanto y dolor contemplar desde el valle los bosques cordilleranos iluminados por los roces (...) Se está incendiando a Chile en nombre de la agricultura, se está decretando el desierto del sur a nombre del trigo (Albert, 1903, p. 17).

El fuego se constituyó en una herramienta político-simbólica para lograr el sometimiento y control de las tierras mapuches, pero también cumplió un rol técnico-productivo para llevar a cabo la explotación de la naturaleza mediante acciones asociadas a la 'quema' y el 'roce'. La Figura 4 muestra los procesos de transformación que ocurrían en Wallmapu/Araucanía. Entre el ganado y el ferrocarril se pueden apreciar al fondo los árboles quemados que se mantienen en pie.

Figura 4. Precordillera de La Araucanía (1910)

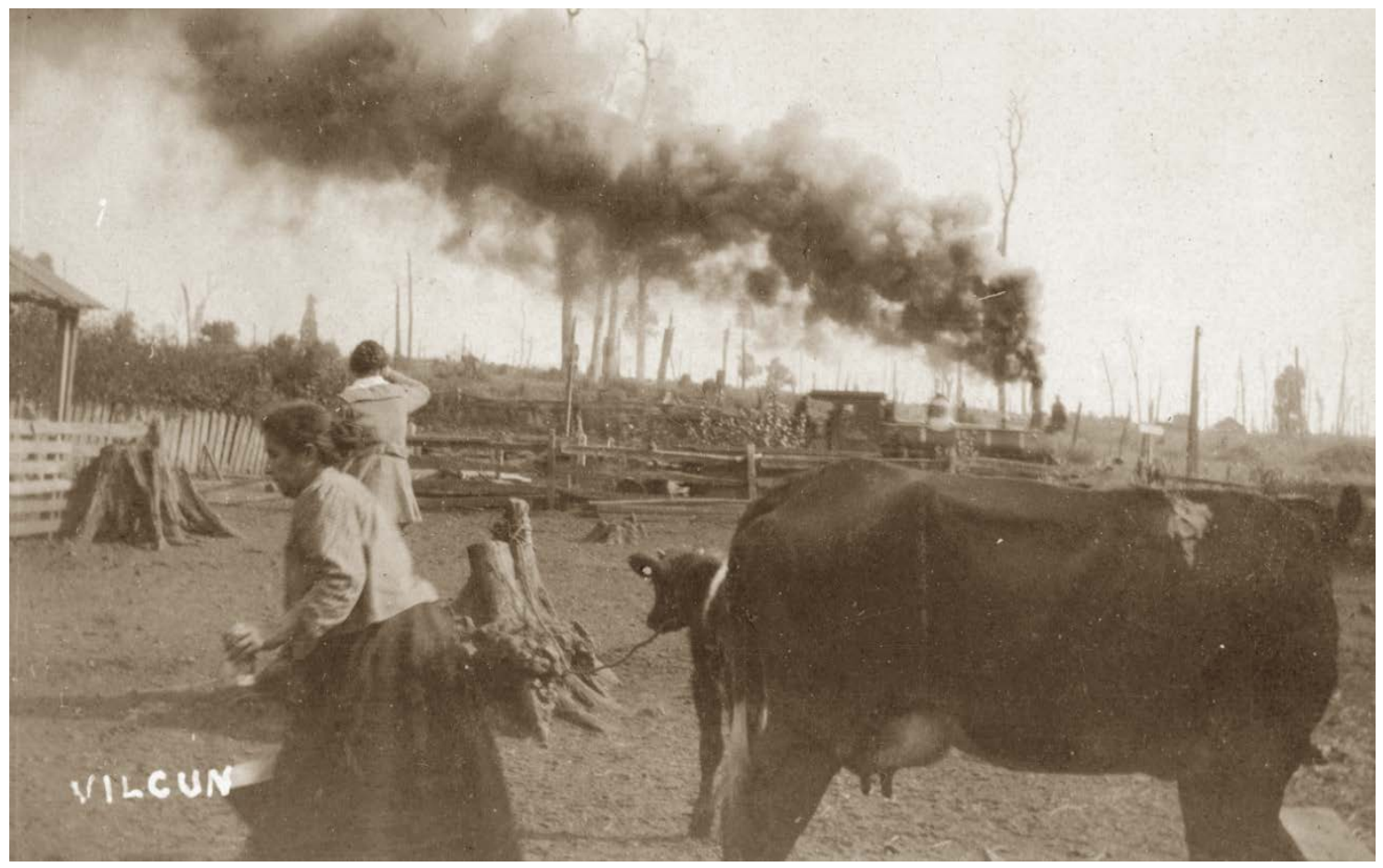

Fuente: Museo Histórico Nacional 
En el marco de estas acciones surgen dos factores que contribuirían a la 'invención' del paisaje forestal del 'Oro verde' en Wallmapu/Araucanía. El primero de ellos se refiere a la necesidad de terminar con las 'quemas' para aprovechar los productos maderables del bosque. Esto resultaba crucial debido a la consolidación de los centros urbanos y la demanda de viviendas que ocurría a nivel regional producto de la migración campo-ciudad (Censo, 1895-1920). Ante esta situación los estudios realizados por Albert adquieren sentido ya que señalaba: "cualquier especie forestal crece en Chile un 30 al 50 \% más rápidamente que en los países de origen, a causa de nuestro clima adecuado para toda clase de cultivos de bosques" (Albert, 1909, p. 51). El pino y el eucalipto se posicionan entonces como los árboles propicios para ser utilizados en esta función debido a que crecían rápidamente tanto en altura como en grosor.

Un segundo factor que incidió fue la erosión provocada por la explotación intensiva del trigo. El hecho que la provincia de Malleco se transformara en el 'Granero de Chile' y proporcionara trigo a países lejanos como Australia y Nueva Zelanda (Correa, 1938; Elizalde, 1958) tuvo consecuencias ambientales desastrosas. La erosión se constituyó en un efecto ambiental negativo que junto con afectar los rendimientos de trigo genero un deterioro significativo del suelo dejándolos inutilizados (Bianchi, 1947).

Bajo este escenario se promulgaron diversas normas legislativas que impulsaron la 'invención' del paisaje forestal. Uno de los primeros fue el Decreto Ley 656 promulgado el 17 de octubre de 1925 sobre bosques, el cual daba cuenta de su relevancia para la economía del país, situación que llevó al Estado a definir cuáles eran los terrenos donde se podría promover la actividad forestal.

Artículo 1. Los fiscales que, previo reconocimiento, sean declarados como tales; Los que los particulares cataloguen en los registros especiales que se abrirán en las cabeceras de provincias y departamentos.

Artículo 4. La declaración de los terrenos que deben someterse a régimen forestal, se hará por períodos de diez en diez años, durante los cuales quedarán exentos de pago de toda contribución.

Artículo 7. Se concede a los particulares, un premio por hectárea de terreno embosquecido (Decreto Ley $N^{0}$ 656, 1925)

La exención del pago de contribuciones fue un aliciente para promover la compra de tierras con el propósito de utilizarlas para llevar a cabo la reforestación. En este contexto, el paisaje boscoso habitado por el pueblo mapuche fue transformado a un paisaje industrial. El Estado chileno 
construyó este proceso, basado en la ciencia como parte del desarrollo nacional. Esta visión hegemónica del uso de suelo, como tabula rasa, involucraba la construcción de otro paisaje: ni indígena, ni Granero. La transformación hacia una región de plantaciones de pino y eucaliptus había comenzado y durante las décadas posteriores reemplazaría gran parte de la agricultura de pequeña escala.

Estos cambios que ocurrian para instalar el paisaje forestal estuvieron vinculados a la invisibilización del pueblo mapuche y su cultura. No obstante, una de las figuras mapuches importantes que surge en este periodo fue Manuel Manquilef, quien a través de algunos escritos hizo notar a la sociedad del país que las costumbres mapuches eran tradiciones igualmente válidas que aquellas realizadas por chilenos y colonos extranjeros. También, denunció los despojos y malos tratos que continuaban ocurriendo ya entrado el siglo XX:

Para pintar la faz social de la vida araucana, ha sido de suma utilidad la descripción de la manera de construir las casas, de los rodeos, de los corrales, en general, de los usos y costumbres; porque descripciones narrativas son uno de los medios de mostrarnos el desarrollo intelectual de un pueblo, pues nos pintan su poder de asimilacion, propio de la inteligencia y la razón (...) los araucanos son tambien hombres provistos de un alma con conocimientos, sentimientos y pensamientos análogos a los de las razas que han creado las naciones más cultas y poderosas de la tierra (Manquilef, 1911, p. 14).

Cuando algunos malos gobernantes de la República se hicieron nuestros amigos, su amistad debilitó el vigor de nuestra raza alcoholizándola, y nos sumió en la miseria arrebatándonos nuestras tierras (Diario Austral, 23 de diciembre de 1916).

En este contexto, es importante entender este proceso racional, cartesiano y vocacional de la 'invención' del 'Oro verde' no solamente como un proceso técnico, con datos procesados y conocimientos derivados de otros continentes, sino como un proceso de coerción y sometimiento cultural. Todo sentido de lugar, custodia y simbolismo del paisaje indígena había sido silenciado por discursos de un nuevo sentido común basado en una modernidad estatal, centralizada, industrial y culturalmente homogénea.

\subsection{La consolidación de una economía basada en las plantaciones forestales (1930-1960)}

La 'invención' del paisaje forestal del 'Oro verde' comienza un proceso de consolidación a partir de leyes, políticas e instituciones. La promulgación del Decreto Ley № 265 contribuyó aclarar 
algunos temas del Decreto promulgado en 1925. Recalificó aquello que se entendía como 'terreno forestal' y aumentó los beneficios:

Artículo 1. Se consideran terrenos forestales: (a) los fiscales que por su composición no sean aptos para sostener en forma económica un cultivo agrícola permanente; (b) los terrenos particulares que teniendo dicho carácter sean declarados como tales a petición de los interesados; (c) los que cualquiera que sea su dueño y teniendo o no carácter de forestales, sea conveniente o necesario que permanezcan arbolados en defensa de algún interés público seriamente amenazado, mencionando una serie de categorías para tal efecto.

Artículo 3. Los plantíos de bosques artificiales existentes o los que se hagan en terrenos declarados o que se declaren forestales, estarán exentos de impuestos por un período de 30 años (Decreto Ley $N^{\circ} 265,1931$ ).

El hecho que aquellos suelos donde no fuera posible llevar a cabo un cultivo resultaban propicios para la actividad forestal generó una especulación importante respecto a todos aquellos que habían sido erosionados por el granero. Por su parte, la exención del pago de contribuciones nuevamente fue un aliciente para promover las plantaciones de pino y eucaliptus y junto con ello promover la compra de tierras, agudizando con ello el conflicto entre el Estado y el pueblo mapuche.

Esta legislación que favorecía el paisaje forestal vino a complementar otras leyes que favorecieron el procedimiento sobre división de comunidades mapuche, estableciendo el título de merced como base de su división, proceso conocido como radicación. En los años sucesivos, la división de las comunidades mapuche facilitó la enajenación y pérdida de tierras indígenas, y consolidó la usurpación dentro de los Títulos de Merced (Informe de la Comisión Histórica y Nuevo Trato, 1999). Las agrupaciones mapuches respondieron a estas legislaciones mediante la organización de reuniones o congresos araucanos donde se discutían, entre otras temáticas, la igualdad con los chilenos principalmente en el tema de las tierras.

Estas demandas no tuvieron eco, es más, durante este periodo en Wallmapu/Araucanía el Ministerio de Industrias y Obras Públicas tuvo un rol central para la materialización de diversas obras viales, que fueron en directo beneficio del paisaje forestal del 'Oro verde'. Fue así como en 1936 se llevó a cabo la habilitación del camino Villarrica-Pucón y se construyeron puentes desde Villarrica al sur con el propósito de favorecer el traslado de maderas hacia Concepción 
(Memoria Ministerio de Industrias y Obras Públicas, 1937). La Figura 5 muestra que a pesar de no contar con caminos adecuados los ríos y lagos servían para movilizar la madera.

\section{Figura 5. Traslado de madera en Pucón (1940)}

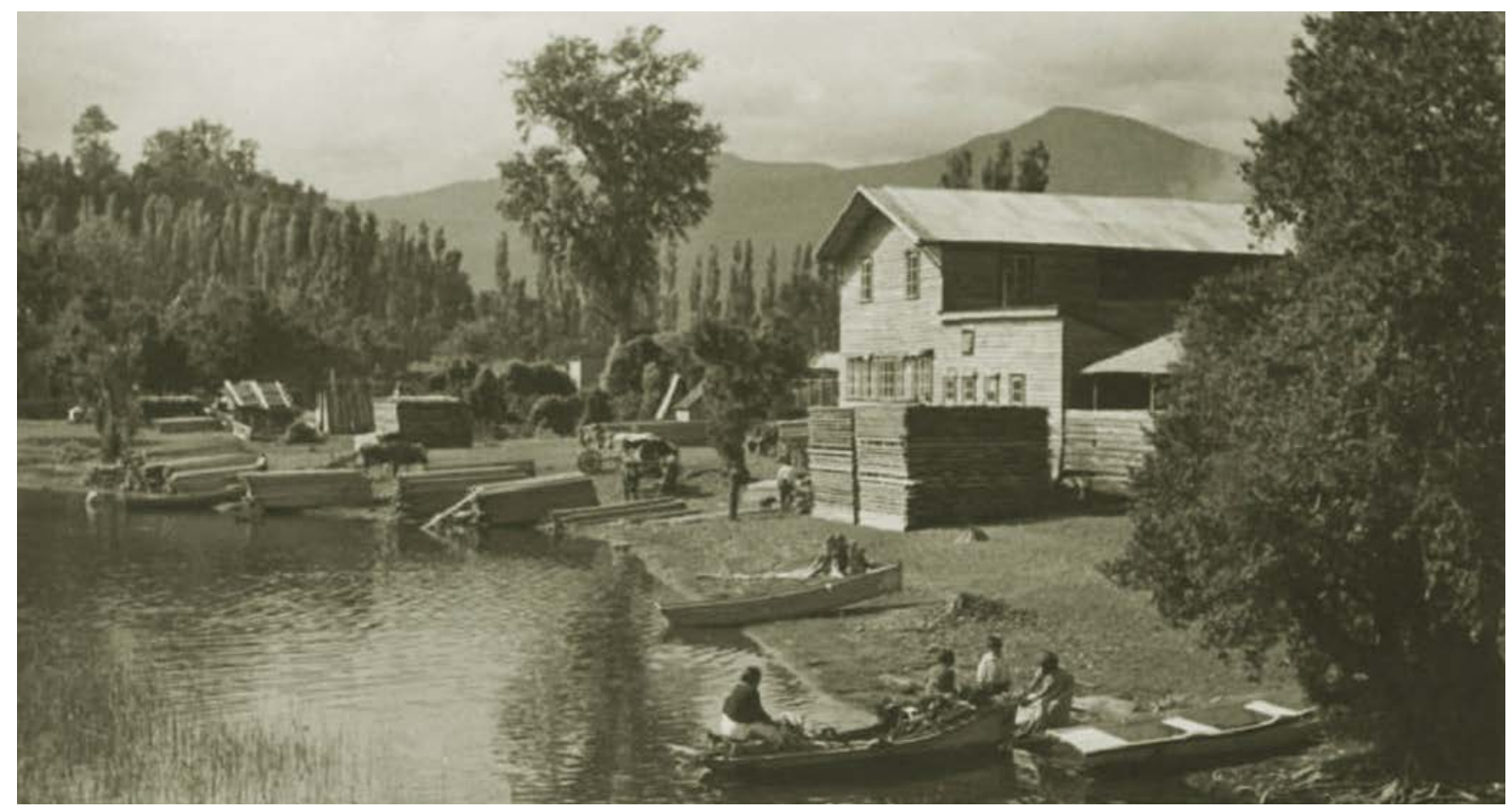

Fuente: Sociedad de Fomento Agrícola de Temuco (SOFO)

La creación en el año 1939 de la Corporación de Fomento de la Producción (CORFO) dio el impulso necesario para la consolidación de la industria forestal mediante el financiamiento de poderes de compra en diversos lugares del país. Estudios realizados por esa entidad planteaban que el país contaba con 1.5 millones de hectáreas maderables, no obstante, hasta ese momento se explotaba solo el $10 \%$ debido a la precariedad de la industria forestal y su bajo nivel tecnológico. Así entonces el rol de la CORFO fue promover desde el Estado la creación de un clima adecuado para la creación de industrias de tipo forestal (CORFO, 1939). En Wallmapu/Araucanía la prensa de la época daba cuenta de estas acciones. El Diario Austral (1940, 1 de abril) titulaba "Corporación inició compra de madera"; en un amplio reportaje se relataba la adquisición por parte de la CORFO de dos fábricas de elaboración de maderas, en Lanco y en Renaico. Con estas fábricas ubicadas a ambos extremos de las provincias de Malleco y Cautín, los bosques y plantaciones de pino y eucaliptus de la región quedaban en un lugar propicio para ser explotados.

La 'invención' del paisaje forestal del 'Oro verde' incluyó también un cambio en los oficios. Las fábricas e industrias requirieron mano de obra especializada, así la región paso de tener solo aserradores y madereros a contar con carpinteros, mecánicos, mueblistas y aserradores, quienes 
se dedicaban principalmente a la fabricación de muebles y durmientes (Tabla 1). La formación de personal especializado en estas tareas recayó inicialmente en escuelas agrícolas que se orientaron hacia el rubro forestal e industrial. Fue así como en 1938 se creó la Escuela de Artesanos en Angol. Por su parte, en 1939 el Liceo industrial de Temuco dictaba un curso en temas forestales que preparaba personal técnico para la industria maderera (Ordenes, 2004).

Tabla 1. Oficios dedicados al ámbito forestal

\begin{tabular}{|c|c|c|c|c|c|}
\hline \multicolumn{3}{|c|}{ Censo 1920 } & \multicolumn{3}{c|}{ Censo 1940 } \\
\hline Oficios & Malleco & Cautín & Oficios & Malleco & Cautín \\
\hline Aserradores & 36 & 161 & Aserradores & 32 & 285 \\
\hline Madereros & 237 & 458 & Carpinteros & 799 & 1662 \\
\hline & & & Mecánicos & 432 & 1133 \\
\hline & & & Mueblistas & 163 & 319 \\
\hline
\end{tabular}

Fuente: elaboración propia en base a Censo de 1920 y 1940

Una de las industrias regionales reconocidas en aquella época fue la Fábrica Mosso, ubicada en Lonquimay. Al respecto, el Diario Austral (1941, 2 de enero) publicaba "1940 fue un año de progreso para la comuna" y explicaba que uno de los factores que contribuyó a ello fue el crecimiento de esta industria que diariamente exportaba una gran cantidad de maderas dando trabajo a más de 500 obreros. La llegada del ferrocarril a Curacautín en 1913 y la construcción del túnel Las Raíces en 1934 resultaron claves para que Juan Bautista Mosso llevara a cabo la instalación de esta industria que entró en marcha en 1938 (Solari et al., 2007).

La proyección del proceso de modernización, progreso y desarrollo que simbolizaba la industria de parte del Estado chileno no consideraba el hecho de que existía diversidad cultural en la región, tampoco que las plantaciones de pino y eucaliptus fueran herramientas de control territorial asociadas a la imposición de un sistema productivo. Por el contrario, la construcción del sentido común hegemónico de esta opción de desarrollo iba de la mano con las plantaciones.

Durante esta década las demandas por el reconocimiento del pueblo mapuche fueron planteadas por Manuel Aburto Panguilef. En carta enviaba al presidente Ibáñez transmite un conjunto de medidas concretas que debían ser consideradas en su programa para mejorar la situación del pueblo mapuche, entre las cuales destacan la creación de escuelas agrícolas, vías férreas y la implementación de una legislación propicia para la propiedad de las tierras (Menard, 2013). Estas mismas interpelaciones fueron presentadas en el Primer Congreso Indigenista Interamericano por Venancio Coñuepan, dirigente del movimiento indígena en Chile y quien, 
junto a Cesar Colima, presentó un trabajo denominado "El problema indígena en Chile". En este documento planteaban:

El Estado Chileno empezó a legislar sobre asuntos indígenas desde mediados del siglo pasado; no obstante, estas leyes fueron defectuosas; porque, desconociéndose la realidad araucana de ese tiempo, dejaron al indio en pequeñas parcelas de suelo; en comunidades; no se consultó el crecimiento de la familia; ni el empobrecimiento de las tierras; fueron aplicadas por elementos venales que favorecían las usurpaciones efectuadas por potentados blancos (Coñuepán \& Colima, 1940, p. 2).

La consolidación de la industria forestal en Wallmapu/Araucanía no estuvo ajena de problemas. Las tensiones entre el pueblo mapuche y los empresarios forestales interesados en orientarse a la producción forestal hicieron surgir nuevamente litigios en torno a la propiedad de la tierra que estaba en manos mapuche. Un actor que presionó para incorporar más suelo a la producción forestal fue la Sociedad de Fomento Agrícola de Temuco (SOFO). En nota del Diario Austral (1946, 6 de octubre) titulada "El fracaso de la ley", se daba conocer un memorándum enviado por la SOFO al Ministro de Tierras y Colonización, en el cual se indicaba que la Ley de División de Comunidades promulgada en 1931 no era favorable para entregar tierras al comercio. Un mes más tarde el mismo matutino publicaba "El cinturón suicida de Cautín estrangula su progreso" (1946, 8 de noviembre; Foerster \& Montecinos, 1988), refiriéndose aquellos terrenos que el pueblo mapuche poseía en las proximidades de Temuco y que debían ser entregados a quienes pudieran realizar alguna actividad agrícola o forestal. Este argumento de baja utilización productiva había sido utilizado en forma constante por fuentes políiticas y empresariales como justificación de la colonización durante el siglo XIX.

Durante el gobierno de Juan Antonio Ríos (1942-1946) se contactó a especialistas extranjeros que instruyeron a los técnicos chilenos en nuevas formas de explotación. Uno de los estudios fue elaborado por el U.S. Departament of Agriculture junto con la CORFO (Irvine et al., 1946). Este documento orientó políticas para impulsar la instalación de aserraderos fijos y portátiles, mejorar las operaciones de las pequeñas fábricas, equipar industrias que se dedicaban al secado, cepillado, fabricación de mobiliario y tejas, además de sugerir expandir la industria de enchapados e instalar una planta de celulosa en Concepción. A partir de este trabajo se generó un cambio radical en las labores forestales. En palabras simples, fue necesario 'cambiar el hacha por la sierra', para ello resultaba clave el diseño y construcción de un tipo adecuado de aserradero que pudiera aumentar la producción de madera por hora. 
Hacia finales de 1949 en materia de forestación se habían invertido a nivel país \$2 924000 en préstamos, aportes a sociedades forestales y establecimientos de viveros, desde la provincia de Atacama hasta Valdivia. Esta inversión permitió aumentar en más de 5000 hectáreas la superficie plantada de pino y eucaliptus. Además, la CORFO organizó junto con la Caja de Colonización Agrícola, la Sociedad Anónima Maderera del Sur y en el rubro de la impregnación de maderas formó en 1947 con aporte de Ferrocarriles del Estado y de particulares la Sociedad Impregnadora de Maderas, que se orientó a la fabricación de durmientes y postes para el mercado interno y externo (CORFO, 1949).

Este incremento de la superficie plantada, se justificaba por la necesidad de los gobiernos de la época de acoger las sugerencias emanadas de organismos internacionales que promovían la consolidación de la industria forestal. Prueba de ello son las actas que surgen del segundo periodo de sesiones realizadas por la CEPAL en Cuba durante junio de 1949 y la tercera reunión de la Comisión Latinoamericana de Bosques y Productos Forestales realizada en diciembre de 1950, las cuales señalan la necesidad de explotar las coníferas presentes en América Latina, que a pesar de abarcar la cuarta parte de la superficie boscosa del mundo y suministrar el 90 por ciento de las necesidades industriales a nivel mundial, no alcanzaban a cubrir la demanda de madera aserrada proveniente de Europa y el Lejano Oriente (CEPAL, 1951).

La 'invención' del paisaje forestal del 'Oro verde' en Wallmapu/Araucanía coincidió con la influencia de estas instituciones internacionales, que se enmarcan en aquello que Escobar denomino 'la invención del tercer mundo', cuyo propósito fue crear las condiciones necesarias para reproducir en todo el mundo los rasgos característicos de las sociedades avanzadas de la época (Escobar, 2007).

Todas estas acciones generaron un clima propicio para la inversión en plantaciones forestales de pino y eucaliptus. El Diario Austral (1951, 7 de marzo) titulaba "Ingentes posibilidades de riqueza maderera serán puesta a disposición de cualquier inversionista". En entrevista realizada al representante de la Comunidad Irarrázaval-Larraín, este mencionaba las altas utilidades asociadas a la comercialización de las parcelas-bosques que esta sociedad tenía ubicadas en Nuble y Biobío. Abogados, industriales y médicos de Temuco habían optado por invertir sus dineros en este instrumento. Al final de la entrevista sentenciaba que "sólo quienes posean bosques de pino conseguirán un cuantioso capital que los mantendrá cubiertos de todos los imprevistos económicos". Otras de las políticas de fomento que contribuyó a la expansión de las 
plantaciones fueron los Viveros Forestales, estos 'pequeños laboratorios' cultivaban plántulas de árboles recién germinados para dispersarlas en las provincias de Malleco y Cautín y conformar el paisaje forestal del 'Oro verde'. El Diario Austral (1951, 7 de marzo) indicaba "un millón de pinos ha vendido Vivero Las Quilas en 15 días". Este vivero se ubicó entre la ciudad de Los Ángeles y Valdivia, por tanto, cubría un amplio territorio favoreciendo con ello la proliferación de este nuevo 'bosque' por toda la región.

La expansión de las plantaciones forestales coincidió también con un crecimiento demográfico regional. Durante los años 1920 a 1940 la población aumentó en 213776 habitantes. Este crecimiento se observa tanto en el ámbito urbano como en el rural. Si bien para el periodo 1940-1952 las cifras disminuyen, se mantiene esta tendencia en el espacio urbano mientras que a nivel rural comienza a disminuir la población (Tabla 2). El aumento de población urbana activó políticas habitacionales para cubrir la demanda de viviendas y los requerimientos de madera crecieron considerablemente. Para ello la región puso en marcha una estrategia que el Diario Austral (1953, 15 de mayo) denominó "Gigantesco plan para el oro verde", que incluía la instalación de una central maderera próxima a Los Lagos, aserraderos dobles mecanizados e industrias de madera prensada para iniciar la construcción de casas prefabricadas.

Este plan también se sustentó en el crecimiento de las plantaciones de pino y eucaliptus que alcanzaban las 79965 hectáreas en la región (Censo Agrícola, 1955) y también en la excesiva explotación del bosque nativo con fines maderables, que estaba llevando a la extinción del raulí, roble y araucaria. Este hecho habría llevado a observar positivamente la reforestación con plantaciones artificiales de pino y eucaliptus, en Galvarino, Loncoche, Freire y Lautaro (Elgueta, 1956). La industria maderera regional contaba en esa época sólo en la provincia de Cautín con más de 130 aserraderos, que la ubicaban como la segunda en importancia a nivel nacional (Fourcade, 1956; Krause, 1956). De esta manera la 'invención' del paisaje forestal del 'Oro verde' se materializaba por diversos lugares de la región y se expresaba a partir de la hegemonía reflejada en las plantaciones que comienzan a dominar la matriz productiva regional. 
Tabla 2. Crecimiento de la población (1920-1952)

\begin{tabular}{|c|c|c|c|c|c|c|c|c|c|c|c|c|}
\hline \multirow[b]{2}{*}{ Provincias } & \multicolumn{4}{|c|}{ Censo 1920} & \multicolumn{4}{|c|}{ Censo 1940} & \multicolumn{4}{|c|}{ Censo 1952} \\
\hline & Urbano & $\%$ & Rural & $\%$ & Urbano & $\%$ & Rural & $\%$ & Urbano & $\%$ & Rural & $\%$ \\
\hline Malleco & 41380 & 35 & 80049 & 65 & 52508 & 34 & 101666 & 27 & 61647 & 34 & 97772 & 29 \\
\hline Cautín & 54190 & 28 & 139438 & 72 & 101483 & 66 & 273176 & 73 & 120923 & 66 & 244149 & 72 \\
\hline Total & 95.570 & & 219487 & & 153991 & & 374842 & & 182570 & & 341921 & \\
\hline $\begin{array}{c}\text { Total } \\
\text { regional }\end{array}$ & \multicolumn{4}{|c|}{315057} & \multicolumn{4}{|c|}{528833} & \multicolumn{4}{|c|}{524491} \\
\hline
\end{tabular}

Fuente: elaboración propia en base a Censos 1920, 1940 y 1952

La transformación del 'Granero de Chile' a un paisaje de plantaciones de pino y eucaliptus no fue una transición casual. Las leyes, las inversiones privadas en maquinaria, las inversiones públicas en subsidios, en viveros, en infraestructura, los nuevos oficios y la urbanización dependían de una construcción social de la región pos-trigo. La nueva vocación, planteada por un Estado desarrollista y apoyado por asesoría internacional, fue la del 'Oro Verde', típico de la lógica modernista de mecanización, especialización y homogenización pos-guerra, tal como Arturo Escobar lo señala. El imaginario forestal vino a suplantar el imaginario de una cultura indígena, viviendo en lof $^{2}$ que gestionaba su subsistencia mediante prácticas de recolección, cultivo y trueque.

\subsection{De la 'invención' a la hegemonía del 'Oro verde' (1960-1990)}

El aumento de las plantaciones forestales en la región no estuvo ajeno al proceso de reforma agraria y las demandas del pueblo mapuche por las tierras usurpadas. Este malestar se acrecentó a partir de la ley que fijó normas sobre la división de las comunidades, liquidación de créditos y su radicación (Ley 14 511, 1961). Este punto resultaba crucial ya que con ello se fragmentaba nuevamente la escasa tierra que pertenecía al pueblo mapuche. En este contexto, se promulgo la ley sobre Reforma Agraria (Ley 15 020, 1962). Desde 1964 a 1970 fueron 25 predios (cerca de 20 mil hectáreas) al interior de la región los que pasaron a constituir tierra mapuche (Correa et al., 2005). Mientras este proceso de reforma agraria se llevaba a cabo, la industria forestal continuaba en proceso de consolidación en la región. El Diario Austral (1964, 27 de mayo) señalaba que 'las plantaciones de pino realizadas entre 1940 a 1950 comenzaban a ser

2 El lof para el pueblo mapuche se constituye en una forma básica de organización social caracterizada por el sentido de comunalidad. Para mayores antecedentes respecto a la organización sociopolítica del pueblo mapuche, ver Quidel, J. (2016). El quiebre ontológico a partir del contacto mapuche hispano. Chungara, Revista de antropología chilena, 48(4), 713-719. 
cosechadas', en su reemplazo eran plantadas nuevas especies que se provenían del vivero Las Quilas y se orientaban principalmente hacia la reforestación de algunos fundos próximos a Temuco, Curacautín, Victoria y Lonquimay. Un detalle de la superficie de pino plantada se puede observar en la Tabla 3.

Tabla 3. Hectáreas plantadas de pino por comuna para los años 1963 a 1966

\begin{tabular}{|c|c|c|c|c|c|}
\hline & & \multicolumn{4}{|c|}{ Años } \\
\hline \multirow[t]{4}{*}{ Provincia } & Comuna & 1963 & 1964 & 1965 & 1966 \\
\hline & Angol & 5,2 & 2,8 & 1134,4 & 323,8 \\
\hline & Purén & & & & 148,6 \\
\hline & \begin{tabular}{|l} 
Los \\
Sauces
\end{tabular} & & & & 9,2 \\
\hline \multirow{6}{*}{ Malleco } & Renaico & & 828 & 355,2 & 512 \\
\hline & Collipulli & 41,6 & 695,6 & 241,2 & 745,2 \\
\hline & Ercilla & 20,4 & 4 & 30,5 & 101,6 \\
\hline & Traiguén & 12,8 & 40,4 & 35,6 & 104,8 \\
\hline & Victoria & & 3,6 & 2,4 & \\
\hline & Lautaro & & & 26,5 & 4,4 \\
\hline \multirow[t]{12}{*}{ Cautín } & Perquenco & & & & 6,2 \\
\hline & Galvarino & & & 5 & 15,5 \\
\hline & $\begin{array}{l}\text { Nueva } \\
\text { imperial }\end{array}$ & & & 22,2 & 17 \\
\hline & Carahue & & & 3 & 14,1 \\
\hline & Temuco & & & 6 & 0,5 \\
\hline & Freire & & & 17,5 & 7,5 \\
\hline & Cunco & & & 22,5 & 14,5 \\
\hline & Gorbea & & & 90 & 5,6 \\
\hline & Toltén & & & 2,4 & \\
\hline & Loncoche & & & 77,6 & 44 \\
\hline & Villarrica & & & 4 & \\
\hline & Pucón & & & 18 & \\
\hline
\end{tabular}

Fuente: elaboración propia en base a INFOR (1967)

Se destaca también el predominio de las plantaciones en las comunas de Angol, Collipulli y Renaico. La proximidad con la provincia de Arauco surge como un factor que podría explicar este aumento; sin embargo, también influyeron las políticas promulgadas a inicios del siglo XX que tuvieron como propósito frenar la erosión ocurrida por la explotación de los suelos del Granero de Chile ubicado en el norte de la provincia de Malleco.

Un paso relevante para consolidar la hegemonía de las plantaciones fue la construcción de plantas de celulosa en el sur del país. Si bien estas se instalaron en la región del Biobío, su proximidad con Wallmapu/Araucanía, favoreció la intensificación de las plantaciones forestales dada la demanda futura. La celulosa Arauco se inició en 1967 con un $75 \%$ de capital provisto 
por la CORFO y el $25 \%$ restante venía de capitales directamente de Estados Unidos, el Reino Unido, Australia y de las compañías norteamericanas Parsons and Whitmore, mientras que en 1969 la CORFO comenzó a construir otra planta de celulosa en Constitución, cuyo capital inicial también fue provisto por el Estado y también con capitales extranjeros franceses además, los fondos para este proyecto fueron provistos por la fundación para el desarrollo de la iglesia católica de Talca (Klubock, 2014). En septiembre de 1979 Celulosa Arauco y Constitución serían privatizadas y se transformarían en una sociedad anónima. En la actualidad es controlada por el grupo económico de la familia Angelini, bajo el nombre de Forestal Arauco.

En este sentido y tal como lo señalamos al inicio del artículo, la Región del Biobío ha concentrado la actividad industrial asociada a las plantaciones forestales, no obstante, la cercanía con la Región de La Araucanía ha transformado este espacio regional en un lugar propicio para intensificar las plantaciones y la instalación de industrias de celulosa, de hecho en 1992 comenzó a operar la primera planta de Celulosa en la región conocida como Planta Pacífico y que pertenece al grupo económico de la familia Matte, denominado CMPC-Forestal Mininco.

El impulso final para la consolidación del paisaje forestal ocurrió bajo la dictadura de Pinochet. Durante este período se dictó el Decreto Ley 701, que buscaba crear un nuevo orden económico e impulsar directamente bonificaciones al sector forestal (Clapp, 1988). Este decreto planteaba:

Artículo 5. Los bosques naturales, artificiales y terrenos de aptitud preferentemente forestal, sea que pertenezcan a personas naturales o jurídicas, incluidas las sociedades anónimas de giro preferentemente forestal, que se acojan a las disposiciones del presente decreto ley, serán inexpropiables.

Artículo 21. Durante el plazo de 10 años, el Estado bonificará en un 75 \% de su valor en la forestación y su manejo que realicen tanto las personas naturales como las personas jurídicas (Decreto 701, 1974).

Estas orientaciones fueron en directo beneficio de los empresarios forestales ya que el Estado aseguraba sus predios dejándolos exentos de la reforma agraria. Con ello se traspasó al sector privado la función ejecutora de las faenas de reforestación, mientras que el rol del Estado quedo marginado solo a aquellos ámbitos en que los empresarios no estaban interesados en desarrollarlas. La Figura 6 da cuenta del crecimiento sostenido de la superficie plantada, en el caso de la provincia de Malleco esta situación se aprecia de forma más clara producto a que 
este espacio fue donde se inició el proceso de reforestación con plantaciones, producto del cambio de uso de suelo agrícola (trigo) al forestal.

Figura 6. Ilustración de la sección Viruta

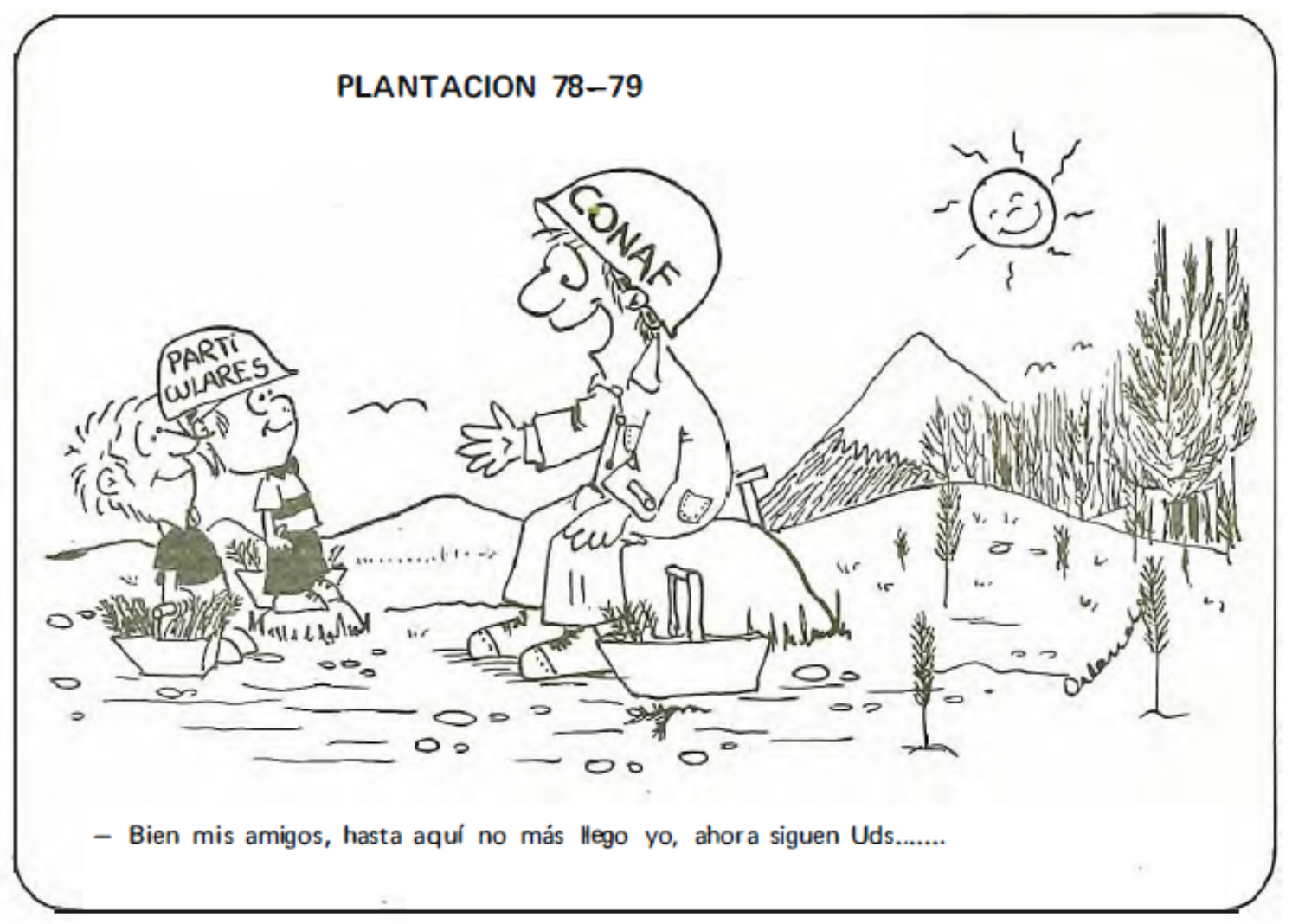

Fuente: extraído de la Revista Chile Forestal, 1978, 4(39), p. 19

Estas medidas generaron un 'boom' forestal en Wallmapu/Araucanía. La Figura 7 permite apreciar cómo a cuatro años del decreto 701 las plantaciones de pino y eucaliptus se distribuyen por toda la región. De los 411 predios acogidos a los beneficios, 127 se encontraban en proceso de calificación o estudio para aplicarles las disposiciones legales. De los restantes, 125 se encontraban en manejo simple, es decir, se estaban realizando acciones para mejorar su capacidad productiva. En manejo más avanzado se encontraban 74; esta característica implicaba que la plantación tenía al menos cinco años. En pleno proceso de forestación se encontraban 60 predios, mientras que en explotación, los restantes 25. El sector norte de la provincia de Malleco concentraba la mayor actividad de predios acogidos al decreto, mientras que las comunas ubicadas al sur de Temuco contaban con predios dedicados principalmente al manejo simple.

Si bien el Decreto 701 contribuyó a aumentar la superficie, su expansión fue promovida tempranamente durante el siglo XX. La Tabla 4 permite observar que previo a 1953, ya existían plantaciones en ambas provincias producto de las políticas establecidas a partir de 1930. 
También es posible identificar que en el período previo al decreto, 1953-1973, existen más de veinte mil hectáreas para ser explotadas. El mayor número se encuentran en el tramo que va desde 1970 a 1983, si bien no superan los 10 años de crecimiento fueron las que sustentarían la industria de celulosa entre 1980 y 1990.

Figura 7. Distribución de las plantaciones forestales

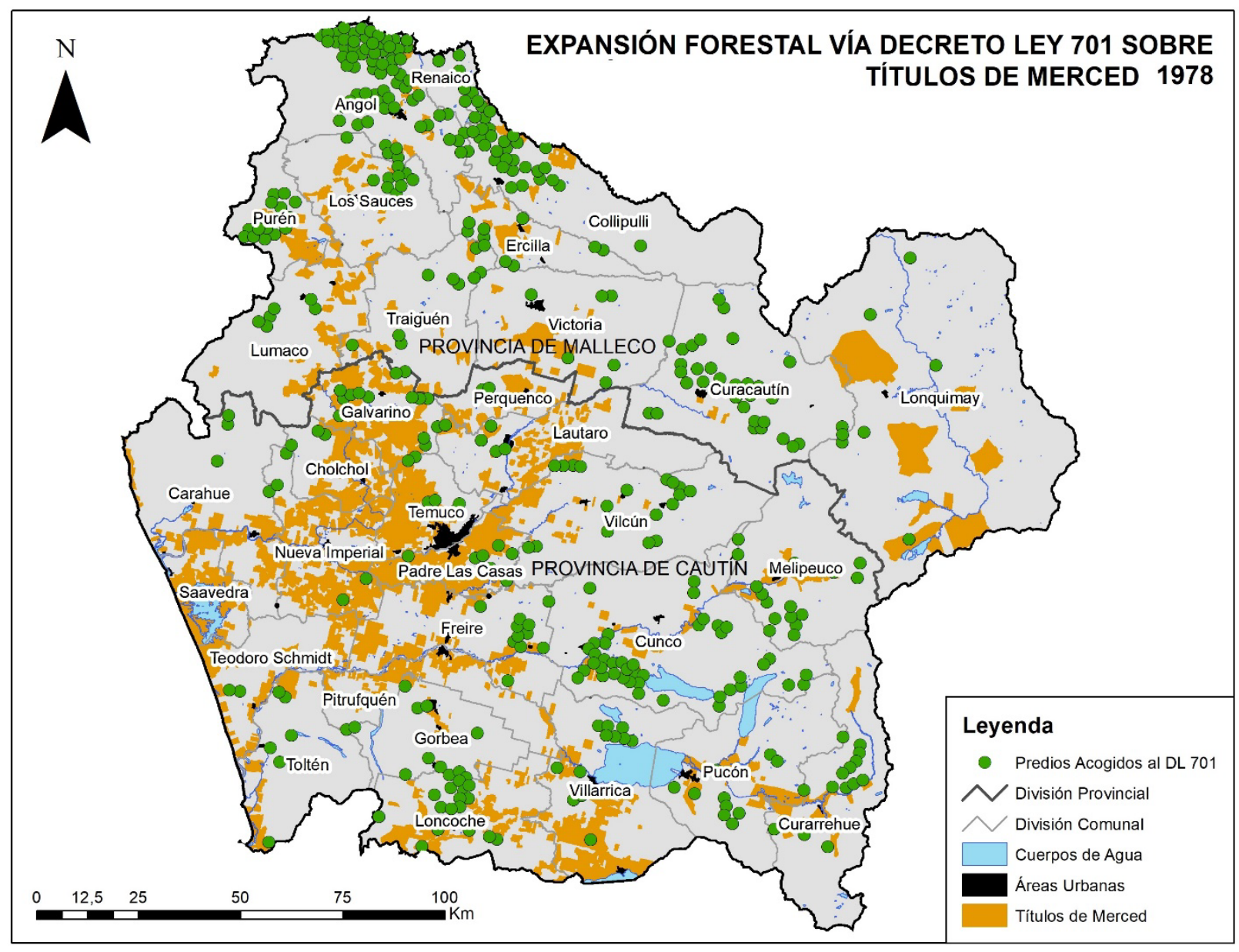

Fuente: elaboración propia en base a Corporación Nacional Forestal (CONAF) (1978) 
Tabla 4. Superficie total de plantaciones

para las provincias de Malleco y Cautín (1953-1983)

\begin{tabular}{|c|c|c|c|}
\hline \multirow{4}{*}{$\begin{array}{c}\text { Provincia } \\
\text { de Malleco }\end{array}$} & Año de plantación & $\begin{array}{c}\text { Edad de la } \\
\text { plantación } \\
\text { (años) }\end{array}$ & Superficie \\
\cline { 2 - 4 } & $1979-1983$ & $1-5$ & 45142,7 \\
\cline { 2 - 4 } & $1974-1978$ & $6-10$ & 23188,9 \\
\cline { 2 - 4 } & $1969-1973$ & $11-15$ & 10499,4 \\
\cline { 2 - 4 } & $1964-1968$ & $16-20$ & 5593,3 \\
\cline { 2 - 4 } & $1959-1963$ & $21-25$ & 2841,1 \\
\cline { 2 - 4 } & $1954-1958$ & $26-30$ & 1576,1 \\
\hline \multirow{4}{*}{$\begin{array}{c}\text { Provincia } \\
\text { de Cautín }\end{array}$} & Antes de 1953 & 31 y más & 1731,2 \\
\cline { 2 - 4 } & $1979-1983$ & $1-5$ & 15781,3 \\
\cline { 2 - 4 } & $1974-1978$ & $6-10$ & 11921,5 \\
\cline { 2 - 4 } & $1969-1973$ & $11-15$ & 4011,3 \\
\cline { 2 - 4 } & $1964-1968$ & $16-20$ & 953,9 \\
\cline { 2 - 4 } & $1959-1963$ & $21-25$ & 649,4 \\
\hline & Antes de 1953-1958 & $26-30$ & 915,3 \\
\hline
\end{tabular}

Fuente: elaboración propia a partir de CORFO (1984)

La 'invención' del paisaje forestal del 'Oro verde' ha generado en las últimas décadas una serie de conflictos socioambientales. Fue así que en el marco de los 500 años del descubrimiento de América (1992) diversas organizaciones mapuches iniciaron un proceso de recuperación territorial que los enfrentó directamente con las empresas forestales (Pairican, 2015). Estas acciones coincidieron con el inicio de la explotación a gran escala de aquellas plantaciones realizadas en la década de 1970, que ya estaban en condiciones de ser incorporadas al proceso productivo. La Figura 8 permite apreciar el aumento sostenido de la superficie plantada a nivel regional, la cual para el año 1993 equivalía al 12\% (357074 hectáreas) de la superficie regional, para el año 1997 aumento al 14,5 \% (450 491 hectáreas) y para el año 2003 ascendía al 17,3\% (537 025 hectáreas), si a ello sumamos la presencia de dos plantas de celulosa, una ubicada en la cercanías de Angol perteneciente a CMPC y la otra ubicada en la región de los Ríos asociada a ARAUCO, posibilitaron, al igual que los invernaderos de mediados del siglo XX que permitieron propagar las semillas de estas especies exóticas, el arribo de la materia prima necesaria para la extracción de celulosa proveniente de las plantaciones que se llevaban a cabo en Wallmapu/Araucanía. 
A la luz de los antecedentes presentados es posible reconocer que este conflicto tiene como eje central el crecimiento de esta actividad sobre los títulos de merced ${ }^{3}$ que pertenecen al pueblo mapuche. La estrategia utilizada ha sido la compra de predios agrícolas aledaños para la 'invención' del paisaje forestal, presionando así a las comunidades cercanas (Figura 8). Estas acciones han traído aparejado efectos en el modo de vida de las comunidades, entre los cuales se puede mencionar el déficit en la disponibilidad de agua para subsistencia, el aumento de incendios forestales, la sustitución y fragmentación del bosque nativo, aumento de la desigualdad y la pobreza, precariedad laboral y disminución de la población rural por migración forzosa a centros urbanos (Latorre \& Rojas, 2016).

La invasión de la actividad forestal y sus efectos sobre las comunidades mapuche se ha transformado en un tema relevante de las diversas interpelaciones al Estado que las comunidades mapuche han realizado en este último tiempo y que se constituyen en acciones propias del descontento producto de un colonialismo sistemático llevado a cabo por el Estado, quien ha aplicado durante el último tiempo constantemente la Ley Antiterrorista (18 314) y encarcelado algunos comuneros por procesos vinculados a la violencia rural.

Al respecto el actual vocero de la organización política mapuche denominada Coordinadora Arauco-Malleco (CAM) Héctor Llaitul Carillanca, ha señalado que "el Estado no nos valida. Lo que valida es supresión de nuestras expresiones. Ni siquiera gestos mínimos de reparación. Es una bofetada al movimiento mapuche, en circunstancias que tenemos una lucha muy frontal con las forestales" (Cooperativa.cl, 2016, January 31).

De alguna manera, las grandes extensiones del 'Oro verde' representan la instalación de un sentido común dominante asociado a la búsqueda del progreso y el desarrollo a cualquier costo, situación que influido en el conflicto Estado-Pueblo mapuche que ocurre en Wallmapu/Araucanía. El 'Oro verde' fue una estrategia de comodificación de la región para el beneficio principalmente de otros, en otras regiones. Para parafrasear a Diana Davis y aplicar sus

3 Los títulos de merced, fueron otorgados por la Comisión Radicadora a las comunidades indígenas ubicadas en las actuales regiones del Biobío, La Araucanía, Los Ríos y Los Lagos entre 1884 y 1929. El artículo 12 de la ley indígena (19 253) promulgada en 1993, establece un conjunto de normas que buscan proteger estas tierras dejándolas fuera del mercado, específicamente, señala que sus propietarios no podrán arrendarlas, darlas en comodato, ni cedidas a terceros en uso, goce o administración. No obstante, dada la presión de los grupos económicos por incorporar más tierra para el desarrollo productivo, durante el año 2019 se propuso eliminar la limitante de que las tierras indígenas comunitarias puedan ser arrendadas a particulares. Situación que aún se encuentra en discusión. 
ideas sobre procesos de transformación en EE.UU. en otro contexto, esta situación refleja la tenacidad de las ideas del Estado chileno para 'inventar' este paisaje forestal en el siglo XX.

Figura 8. Expansión de las plantaciones en Wallmapu/Araucanía (1994-2003)
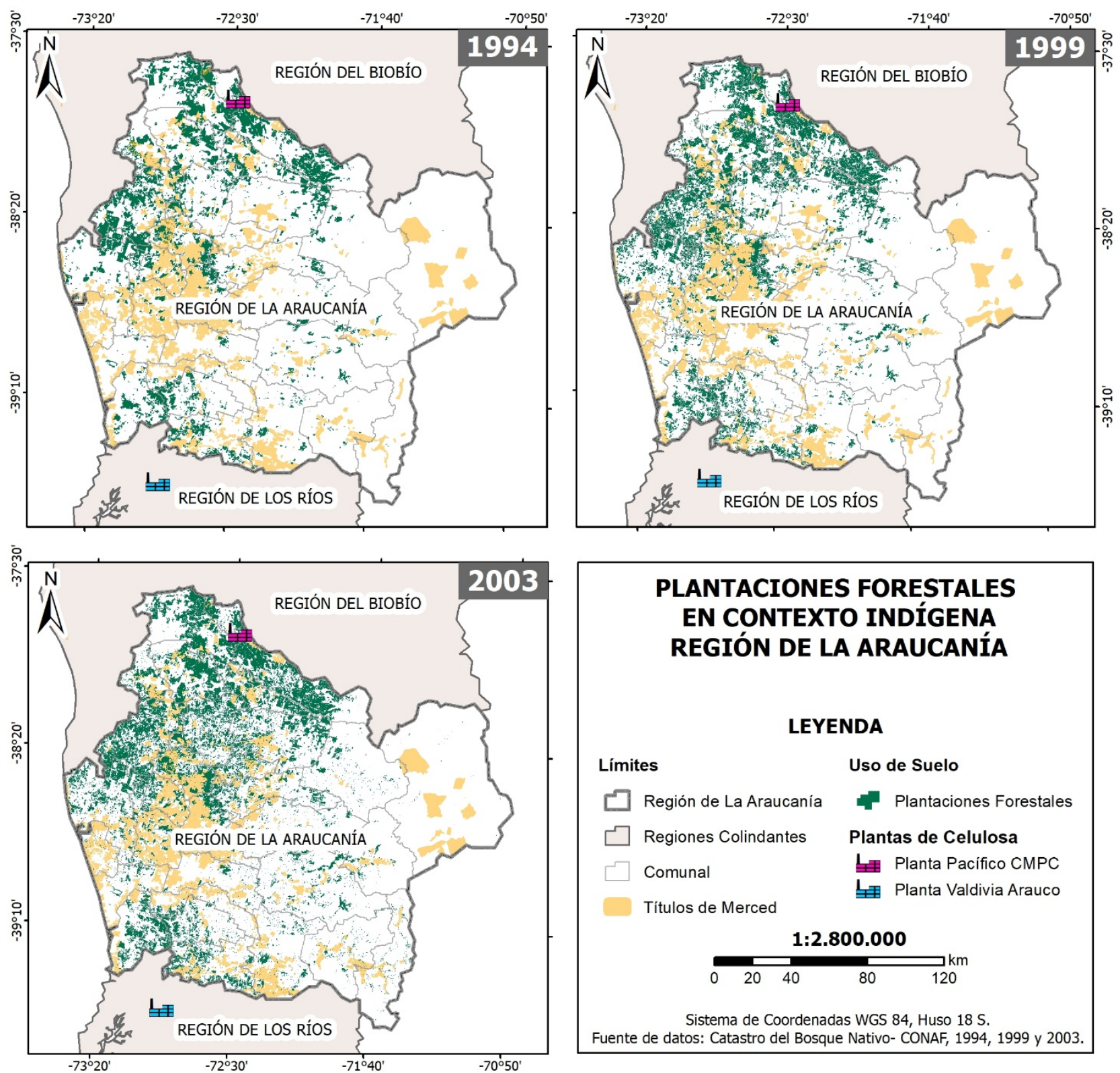

\section{PLANTACIONES FORESTALES EN CONTEXTO INDÍGENA REGIÓN DE LA ARAUCANÍA}

\section{LEYENDA}

Límites

Región de La Araucanía

Regiones Colindantes

Comunal

Títulos de Merced

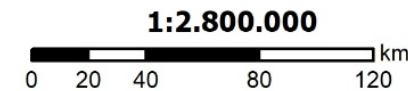

Sistema de Coordenadas WGS 84 , Huso $18 \mathrm{~S}$. Fuente de datos: Catastro del Bosque Nativo- CONAF, 1994, 1999 y 2003.

Fuente: elaboración propia

\section{Conclusiones: una geografía histórica de la construcción de un paisaje de exclusión}

El ser humano forma parte del paisaje y lo transforma a través de la cotidianeidad de su habitar.

Estos cambios no resultan casuales, sino que se encuentran influenciados por factores políticos, 
económicos y socio-culturales. El marco teórico-conceptual de los paisajes de poder, dentro del campo de la ecología política histórica, proporciona una herramienta útil para trabajar estudios de casos de conflictos socio-ecológicos históricos y contemporáneos. En la mayoría de los trabajos sobre ecología política, los paisajes proporcionan el telón de fondo para entender las relaciones de poder - de dominación, explotación, exclusión y resistencia- que se presentan en los conflictos actuales. Para leer o interpretar este telón es necesario avanzar en las conceptualizaciones de paisaje, desde la fenomenología y la vivencia hacia los actores, intereses y dispositivos asociados a las relaciones de poder. El paisaje no es producido a través de su cambio físico y 'natural' sino por las intenciones e intereses de cierto grupo de actores, y las formas en las cuales construyen socialmente la vocación territorial para un desarrollo moderno, científico, industrial y nacional. La hegemonía ejercida sobre un territorio depende de esta construcción y la insistencia en ella durante décadas, hasta que la mayoría de las personas lo conciben como un sentido común, produciendo así consentimiento que no requiere coerción más directa o violenta, según Gramsci. Sin embargo, donde hay hegemonía, hay fuerzas contrahegemónicas emergentes, con otras narrativas y reclamos.

La 'invención' y consolidación del paisaje forestal del 'Oro verde' en Wallmapu/Araucanía se llevó a cabo a lo largo de una trayectoria que se traza a partir de las 'bondades' que presentaba este territorio para acoger una economía basada en las plantaciones forestales durante el siglo XX. Diversos dispositivos fueron utilizados para transformar el paisaje y reemplazar las selvas de antaño por especies exóticas. Leyes, decretos, nuevas instituciones, asesoría de organismos internacionales, entre otros elementos, resultaron claves para instalar definitivamente la industria forestal y desplegar las plantaciones por las diversas comunas y provincias de la región. El paisaje del 'Oro verde' contribuye a reflexionar respecto a las acciones de apropiación de la naturaleza y la hegemonía cultural que han posibilitado la instalación de un sentido común dominante en este territorio asociado al progreso y desarrollo, y a través de la negación de otra cultura y la usurpación de su paisaje. Esta situación ha generado que el conflicto actual entre el Estado chileno y el pueblo mapuche tiene como eje central el crecimiento de esta actividad sobre los títulos de merced. Las alternativas para reducir el conflicto en este territorio van de la mano de un reconocimiento de las formas e instrumentos a través de las cuales el paisaje actual ha sido construido socialmente. De la misma manera que fue construido, puede ser también reconstruido, bajo una lógica de inclusión y un reconocimiento de otros derechos y saberes. La reinvención es la esencia de los paisajes culturales, y es por eso que los derechos ancestrales de otros pueblos colonizados han sido 
reconocidos en países como Canadá, Australia y Nueva Zelanda. En Chile, en contraste, la fase de dominación por el Oro Verde persiste.

Agradecimientos: Los autores agradecen el financiamiento de la Agencia Nacional de Investigación y Desarrollo de Chile (ANID) a través de los siguientes proyectos: Beca de doctorado nacional 21150455, Fondecył Regular 1191239 y Fondap/CEDEUS/15110020.

Declaración responsable: Las/os autoras/es declaran que no existe ningún conflicto de interés con relación a la publicación de este artículo. Las tareas se han distribuido de la siguiente manera: el artículo ha sido coordinado por M. Escalona; M. Escalona realizó la investigación y elaboró las figuras; y el artículo fue escrito y editado por ambos autores. 


\section{Bibliografía}

Agnew, J. (2003). Contemporary political geography: intelectual heterodoxy and its dilemas. Political Geography, 22, 603-606. https://doi.org/10.1016/S0962-6298(03)00063-5

Alberts, F. (1903). Los bosques en el país. Santiago: Imprenta Moderna.

Alberts, F. (1909). Los 7 árboles forestales más recomendables para el país. Santiago: Cervantes.

Barthes, R. (1986). Lo obvio y lo obtuso. Imágenes, gestos y voces. Barcelona: Paidós.

Batterbury, S. (2015). Doing political ecology inside and outside the academy. In R. Bryant (Ed.), The International Handbook of Political Ecology (pp. 27-43). London: Edward Elgar.

Bhabha, H. (2002). El lugar de la cultura. Buenos Aires: Manantial.

Blaikie, P., \& Brookfield, H. (1987). Land degradation and society. London: Routledge.

Bianchi, V. (1947). Erosión. Cáncer del suelo. Santiago: Imprenta Universitaria.

Burke, P. (2001). Visto y no visto. El uso de la imagen como documento histórico. Barcelona: Crítica.

Camus, P. (2006). Ambiente, bosques y gestión forestal en Chile. 1541-2005. Santiago: LOM.

Carrasco, N., \& Aliste, E. (2017). Ciudad y desarrollo: imaginario empresarial y forestal en Concepción, Chile. Cuadernos de Vivienda y Urbanismo, (10), 619. hitps://doi.org/10.11144/Javeriana.cvu10-20.cdie

Cassirer, E. (2014). Las ciencias de la cultura. México: Fondo de Cultura Económica.

Comisión Económica para América Latina y El Caribe (CEPAL) (1951). Informe sobre importancia de los bosques y de la producción forestal en la economía Latinoamericana. Cuarto periodo de sesiones. CEPAL. Retrieved from https://www.cepal.org/es/events/past/date/1951

Convenio europeo del Paisaje (2000). Firmado en Florencia el 20 de octubre de 2000. Retrieved from https://rm.coe.int/16802f3fbd

Coñuepán, V., \& Colima, C. (1940). El Problema Indígena de Chile. Acta del Primer Congreso Indigenista Interamericano realizado en México. 
Cooperativa.cl (2016, January 31). Héctor Llaitul: "Tenemos una lucha muy frontal con las forestales". In Cooperativa.cl. Retrieved from

https://www.cooperativa.cl/noticias/pais/pueblos-originarios/mapuche/hector-llaitul-tenemosuna-lucha-muy-frontal-con-las-forestales/2016-01-31/201023.html

Corporación de Fomento de la Producción (CORFO) (1939). Plan de fomento industrial. Santiago: Universo.

Corporación de Fomento de la Producción (CORFO) (1949). Esquema de diez años de labor, 1939-1949. Santiago: Zig-Zag.

Corporación de Fomento de la Producción (CORFO) (1984). Prospección plantaciones forestales IX Región, Volumen VII, mes de Julio. Santiago: Zig-Zag.

Correa, L. (1938). Agricultura chilena. Santiago: Imprenta Nacimiento.

Correa, M., Molina, R., \& Yañez, N. (2005). La Reforma Agraria y las Tierras Mapuche. Santiago: LOM.

Cosgrove, D., \& Daniels, S. (1988). The iconography of landscape: Essays on the Symbolic Representation, Design and Use of past Environments. Cambridge: University Press.

Clapp, A. (1998). Waiting for the forest law: Resource-led development and environmental politics in Chile. Latin American Research Review, (33), 3-36. Retrieved from https://www.jstor.org/stable/2504061?seq=1

Crow, J. (2013). The Mapuche in modern Chile: a cultural history. Gainesville: University Press of Florida.

Davis, D. (2009). Historical political ecology: On the importance of looking back to move forward. Geoforum, 40(3), 285-286. http://dx.doi.org/10.1016/j.geoforum.2009.01.001

Davis, D. (2015). Historical approaches to political ecology. In G. Bridge, J. McCarthy \& T. Perrault (Eds.), The handbook of political ecology (pp. 263-275). London: Routledge.

Davis, D. (2016). The Arid Lands: History, power, knowledge. Cambridge: MIT Press.

De la Maza, F. (2014). Between conflict and recognition: The construction of Chilean indigenous policy in the Araucanía region. Critique of Anthropology, (34), 34666. https://doi.org/10.1177/0308275X14531836 
Del Casino, V., \& Hanna, S. (2006). 'Beyond the Binaries: A Methodological Intervention for Interrogating Maps as Representational Practices. International E-Journal for Critical Geographers, (1), 34-56. Retrieved from https://www.acme-journal.org/index.php/acme/article/view/727

Di Giminiani, P. (2012). Tierras ancestrales, disputas contemporáneas: Pertenencia y demandas territoriales en la sociedad Mapuche rural. Santiago: Ediciones Universidad Católica de Chile.

Di Giminiani, P. (2015). The becoming of ancestral land: Place and property in Mapuche land claims. American Ethnologist, (42), 490-503. https://doi.org/10.1111/amet.12143

Diario Austral, 23 de diciembre de 1916.

Diario Austral, 1 de abril de 1940, p. 26

Diario Austral, 2 de enero de 1941, p. 6.

Diario Austral, 6 de octubre de 1946, p, 5.

Diario Austral, 8 de noviembre de 1946, p, 8.

Diario Austral, 7 de marzo de 1951, p. 7.

Diario Austral, 7 de marzo de 1951, p. 8.

Diario Austral, 15 de mayo de 1953, p. 3.

Diario Austral, 27 de mayo de 1964, p. 7.

Donnelly, M., \& Norton, C. (2011). Doing history. London-New York: Routledge.

El Campesino (1875). Boletín de la Sociedad Nacional de Agricultura, VI(11). Santiago: Imprenta Chilena.

El Campesino (1901). Boletín de la Sociedad Nacional de Agricultura, XXXII(46). Santiago: Imprenta Chilena.

Elizalde, R. (1958). La sobrevivencia de Chile. Santiago: Ministerio de agricultura.

Elgueta, H. (1956) Bosque y reservas de la provincia de Cautín. Seminario de investigación sobre el desarrollo de la provincia de Cautín. Ediciones Universidad de La Frontera.

Errázuriz, F. (1892). Tres Razas. Santiago: Imprenta de la Patria.

Escalona Ulloa, M. (2019). Paisaje, poder y transformaciones territoriales en Araucanía, 18461992: Una ecología política histórica (Doctoral dissertation, Pontificia Universidad Católica de Chile, Chile). Retrieved from https://repositorio.uc.cl/ 
Escalona Ulloa, M. (2020). Transformaciones territoriales en Wallmapu/Araucanía. Una ecología política histórica. In M. Escalona Ulloa, A. Muñoz-Pedreros \& D. Figueroa Hernández (Eds.), Gobernanza ambiental. Reflexiones y debates desde La Araucanía (pp. 19-70). Santiago: RIL Editores.

Escalona Ulloa, M., \& Barton J.R. (2020). A 'Landscapes of Power' framework for historical political ecology: The production of cultural hegemony in Araucanía-Wallmapu. Area, (52), 445 454. https://doi.org/10.1111/area. 12591

Escobar, A. (2007). La invención del tercer mundo. Construcción y deconstrucción del desarrollo. Caracas: Editorial el perro y la rana.

Femia, J. (1987). Gramsci's political thought. New York: Clarendon Press.

Foerster, R., \& S. Montecinos. (1988). Organizaciones, líderes y contiendas mapuches (19001970). Ediciones Centro de Estudios de la Mujer, Santiago.

Fourcade, M. (1956). La industria de la madera. Seminario de investigación sobre el desarrollo de la provincia de Cautín. Ediciones Universidad de La Frontera.

Galeano, E. (2004). Las venas abiertas de América Latina. México: Siglo XXI.

Gobierno de Chile (1885). Censo General de la República de Chile. Levantado el 26 de noviembre de 1895. Tomo Primero. Valparaíso. Imprenta La Patria.

Gobierno de Chile (1907). Censo General de la República de Chile. Levantado el 28 de noviembre de 1907. Tomo Cuarto. Santiago. Imprenta del Universo.

Gobierno de Chile (1920). Censo Nacional de Población de Chile. Realizado el día 15 de diciembre de 1920.

Gobierno de Chile (1940). Censo Nacional de Población de Chile. Realizado el día 28 de noviembre de 1940 .

Gobierno de Chile (1955). Censo Nacional Agrícola y Ganadero. Santiago de Chile, Abril.

Gobierno de Chile (1999) Informe de la Comisión Verdad Histórica y Nuevo Trato (1999). Volumen 2. Anexo. Santiago de Chile.

Gramsci, A. (1999). Cuadernos de la cárcel. Tomo 5. México: Era Ediciones.

Harley, J. (1989). Deconstructing the Map. Cartographica, (26), 120. https://doi.org/10.3138/E635-7827-1757-9T53 
Hevilla, C. (2007). Los viajeros de las alturas: narrativas de viajeros y científicos sobre los Andes argentino-chilenos en el siglo XIX. In P. Zusman, C. Lois \& H. Castro (Eds.), Viajes y Geografía (pp. 67-92). Buenos Aires: Prometeo.

Husserl, E. (1962). Ideas, relativas a una fenomenología pura y una filosofía fenomenológica. Barcelona: Paidós.

Instituto Forestal (INFOR) (1967). Reactualización del inventario de las plantaciones forestales 1963-1966. Santiago: INFOR

Ingold, T. (1993). The Temporality of the Landscape. World Archaeology, (25), 152-174. Retrieved from http://www.jstor.org/stable/124811

Iggers, G. (1965). The Idea of Progress: A Critical Reassessment. The American Historical Review, (71), 1-17. https://doi.org/10.1086/ahr/71.1.1

Irvine, H., Teesdale, L., Briegleb, P., Payne, B., \& Haertel, M. (1946). Forest Resources of Chile as a Basis for industrial Expansion. Forest Service of the U.S. Departament of agriculture in cooperation with Corporación de Fomento de la Producción. Santiago: CORFO.

Jackson, P. (1989) Maps of Meaning: An Introduction to Cultural Geography. London: Unwin Hyman.

Kipping, M. Wadhwani, D., \& Bucheli, M. (2014). Analyzing and Interpreting Historical Sources: A Basic Methodology. In M. Bucheli \& D. Wadhwani (Eds.), Organizations in Time: History, Theory, Methods, (pp. 306-329). Oxford: Oxford University Press.

Klubock, T. (2014). La frontera. Forests and ecological conflict in chile's frontier territory. Durham and London: Duke University Press.

Krause, F. (1956). Posibilidades industriales de la provincia de Cautín. Seminario de investigación sobre el desarrollo de la provincia de Cautín. Temuco: Ediciones Universidad de La Frontera.

Latorre, J., \& Rojas, N. (2016). El conflicto forestal en territorio mapuche hoy. Revista de ecología política, (51), 84-87.

Lowenthal, D. (1961). Geography, experience, and imagination: towards a geographical epistemology. Annals of the Association of American Geographers, (51), 241 260. https://doi.org/10.1111/j.1467-8306.1961.tb00377.x

Maderuelo, J. (2005) El paisaje. Génesis de un concepto. Madrid: Abada Editores. 
Mamalakis, M. (1982) Historical Statistics of Chile. Forestry and related activities. United States of América. Greenwood Press: Greenwood Press.

Manquilef, M. (1911) Comentarios del pueblo araucano (la faz socia). Revista de folclore chileno, tomo II. Santiago: Cervantes.

Mansoulet, J. (1893). Guía-crónica de la frontera araucana de Chile. Años 1892-93. Santiago: Imprenta Barcelona.

Marimán, J., Canuiqueo, S., Millalén, J., \& Levil, R. (2006). Escucha Winka! Cuatro ensayos de historia nacional Mapuche y un epílogo sobre el futuro. Santiago:LOM.

Martínez Alier J. (2015). Ecología política del extractivismo y justicia socio-ambiental. InterDisciplina, (3), 57-73, http://dx.doi.org/10.22201/ceiich.24485705e.2015.7.52384

Martin, J. (2002). The political logic of discourse: A neo-Gramscian view history of European. Ideas, (28), 21 -31. https://doi.org/10.1016/S01916599(02)00004-9

Mathevet, R., Peluso N., Couespel, A., \& Robbins, P. (2015). Using historical political ecology to understand the present: water, reeds, and biodiversity in the Camargue Biosphere Reserve, southern France. Ecology and Society, 20(4), 17. http://dx.doi.org/10.5751/ES-07787-200417 McKinnon, I., \& Colleen, H. (2015) (Re)considering regional political ecology? Journal of Political Ecology, (23), 115-203. https://doi.org/10.2458/v23i1.20182

Meinig, D. (1979). The interpretation of ordinary landscapes. New York: Oxford University Press. Menard, A. (2013). Libro diario del presidente de la Federación Araucana, 1940, 1942, 19481951. COLIBRIS Ediciones: Santiago.

Ministerio de Industria y obras públicas (1937). Memoria anual. Santiago: Imprenta nacional.

Mitchell, D. (2001). The lure of the local: landscape studies at the end of a troubled century.

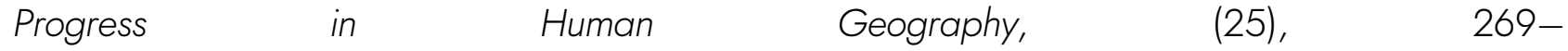
281. https://doi.org/10.1191/030913201678580520

Mitchell, D. (2002). Cultural landscapes: the dialectical landscape-recent landscape research in human geography. Progress in Human Geography, (26), 381 389. https://doi.org/10.1191/0309132502ph376pr

Mitchell, D. (2008). New axioms for reading the landscape: Paying attention to political economy and social justice. In J. L. Wescoat \& D. M. Johnston (Eds.), Political economies of landscape change (pp. 29-50). New York: Springer. 
Muir, R. (1998). Landscape: A Wasted Legacy. Area, (30), 263271. https://doi.org/10.1111/j.1475-4762.1998.tb00071.x

Nahuelpan Moreno, H., Marimán Quemenado, P., Huinca Puitrin, H., \& Carcamo-Huechante, L. (2012). Ta in fijke xipa rakizuameluwün: historia, colonialismo y resistencia desde el país Mapuche. Santiago: Ediciones Comunidad de Historia Mapuche.

Neumann, R. (2011). Political ecology III: Theorizing landscape. Progress in Human Geography, (35), 843-850. https://doi.org/10.1177/0309132510390870

Nogue, J. (2010). El retorno al paisaje. Enrahonar, (45), 123136. https://doi.org/10.5565/rev/enrahonar.224

Offen, K. (2004). Historical Political Ecology: An Introduction. Historical Geography, (32), 19-42. Retrieved from

https://ejournals.unm.edu/index.php/historicalgeography/article/view/2952/2431

Olwig, K. (1996) Recovering the Substantive Nature of Landscape. Annals of the Association of American Geographers, (86), 630-653. https://doi.org/10.1111/j.1467-8306.1996.tb01770.x

Olwig, K., \& Mitchell, D. (2009) Justice, Power and the Political Landscape. New York: Routledge.

Ordenes, M. (2004) La actividad maderera en la provincia de Cautín, 1900-1950 (Doctoral dissertation, Universidad de La Frontera, Chile) (Unpublished).

Pairican, F. (2015). Weuwaiñ: la invención de la tradición en la rebelión del movimiento mapuche (1990-2010). In J. Pinto, I. Goicovich, F. Pairican, S. Caniuqueo, C. Del Valle, J. Mariman \& H. Llaitul (Eds.), Conflictos étnicos, sociales y económicos: Araucanía 1900-2014 (pp.187-214). Santiago: Pehuén.

Perreault, T., Bridge G., \& McCarthy, J. (2015). Editor's introduction. In T. Perreault, G. Bridge \& J. McCarthy (Eds.), The Routledge Handbook of Political Ecology (pp. 3-18). Routledge: New York.

Rydin, Y. (2003). Conflict, consensus, and rationality in environmental planning. An institutional discourse approach. New York: Oxford University Press.

Sauer, C. (1925). The Morphology of Landscape. In John Leigh (Ed), Land \& Life. A selection from the writings of Carl Ortwin Sauer (pp. 315-350). Berkeley \& Los Angeles: University of California Press. 
Simmel, G. (2012). Filosofía del paisaje. Madrid: Casimiro Libros.

Shamma, S. (1997) Landscape \& Memory. New York: Vintage Books.

Schlögel, K. (2007). En el espacio leemos el tiempo. Sobre historia de la civilización y geopolífica. Madrid: Ediciones Siruela.

Tuan, Y. F. (1974). Topofilia. Un estudio de las percepciones, actitudes y valores sobre el entorno. Barcelona: Melusina.

Vermeylen, S., Davies, G., \& Van der Horst, D. (2012). Deconstructing the Conservancy Map: Hxaro, N!ore, and Rhizomes in the Kalahari. Cartographica, (47), 121134. https://doi.org/10.3138/carto.47.2.121

Verniory, G. (2001). Diez años en Araucanía, 1889-1899. Santiago: Pehuén.

$\underline{\text { Cuerpos legales }}$

Decreto Ley N $N^{\circ} 656$ promulgado el 17 de octubre de 1925. Retrieved from https: / /www.ben.cl/leychile/navegar?i=147723\&f=1925-11-06

Decreto Ley № 265 del 26 de mayo de 1931. Retrieved from https://www.bcn.cl/leychile/navegar?idNorma=19422

Decreto Ley № 701 de octubre de 1974. Retrieved from hittps: //www.bcn.cl/leychile/navegar?idNorma=6294

Ley №14 511 que establece los Juzgados de Indios, promulgada el 03 de enero de 1961. Retrieved from https://www.bcn.cl/leychile/navegar?idNorma=27739\&buscar=14511

Ley № 15020 de Reforma Agraria Chilena, publicada el 27 de noviembre de 1962. Retrieved from https: //www.bcn.cl/leychile/navegar?idNorma=28016 